\title{
Kinetic Modeling and Sensitivity Analysis of Plasma-Assisted Oxidation in a $\mathrm{H}_{2} / \mathrm{O}_{2} /$ Ar Mixture
}

\author{
Kuninori Togai, Nicholas Tsolas, and Richard A. Yetter \\ Department of Mechanical and Nuclear Engineering, The Pennsylvania State University \\ University Park, PA 16802, U.S.A.
}

\begin{abstract}
A numerical scheme describing the oxidation process induced by single and multiple dielectric barrier discharges in a $\mathrm{H}_{2} / \mathrm{O}_{2} / \mathrm{Ar}$ mixture is developed. Path flux and sensitivity analyses are performed in order to identify important reaction paths. The analyses are conducted for an initial mixture of $2000 \mathrm{ppm} \mathrm{H}_{2}$ and $3000 \mathrm{ppm} \mathrm{O}_{2}$ balanced in $\mathrm{Ar}$ at a constant pressure of $1 \mathrm{~atm}$ and temperatures ranging from $474 \mathrm{~K}$ to $1008 \mathrm{~K}$, covering both below and above the second explosion limit. Results with only one discharge as well as with repetitive discharges at rates between $1 \mathrm{kHz}$ and $5 \mathrm{kHz}$ are discussed. Three sets of reaction schemes leading to $\mathrm{H}_{2} \mathrm{O}$ formation are identified: two short-time-scale schemes involving negative ions and $\mathrm{O}\left({ }^{1} \mathrm{D}\right)$, respectively, and a long-timescale scheme involving ground state radicals, which is responsible for the majority of the $\mathrm{H}_{2} \mathrm{O}$ formation and driven by plasma dissociation of $\mathrm{H}_{2}$ and $\mathrm{O}_{2}$. At temperatures below the second explosion limit, the last scheme drives the straight chain propagation mechanism without causing exponential growth of radicals, where the reactions of $\mathrm{HO}_{2}$ play important roles on the overall fuel oxidation. At temperatures above the second explosion limit, $\mathrm{H}$ and $\mathrm{O}$ atoms produced from the dissociation of reactants by deactivation of excited argon subsequently trigger ignition significantly reducing the ignition delay. The consumption of $\mathrm{H}_{2}$ and $\mathrm{O}_{2}$ which follows is governed by conventional high temperature chain branching kinetics and occurs at a rate equivalent to that of the purely thermal reaction. Increasing the pulse repetition rate of the discharge at low temperatures results in a shift of the rate-limiting steps from reactions of $\mathrm{H}$ atoms to those of the $\mathrm{OH}$ radical. Furthermore, the kinetics of metastable $\mathrm{Ar}^{*}{ }^{*}, \mathrm{HO}_{2}, \mathrm{O}_{2}\left(a^{1} \Delta_{\mathrm{g}}\right)$, and $\mathrm{O}\left({ }^{1} \mathrm{D}\right)$ are analyzed and their implications to other systems are discussed.
\end{abstract}

Keywords: Plasma assisted combustion; Nanosecond plasma discharge; Kinetic modeling; Sensitivity analysis 


\section{Introduction}

One of the major challenges in developing a scramjet engine is dealing with the short flow residence time in the combustor. If the order of the characteristic chemical reaction time for combustion is longer than the flow residence time, the engine will simply not work [1]. Recently, the use of non-equilibrium plasma discharges to influence combustion processes has attracted interest as the means to overcome this issue [2-5]. The primary attraction of this technique, called plasma-assisted combustion (PAC), is that it enables volumetric energy injection into the internal degrees of freedom (DOF) of the gas molecules, which may efficiently accelerate the overall oxidation process of the fuel. This is a unique feature of PAC in that non-equilibrium plasmas have the potential of in situ production of reactive species at desirable times or spatial locations in the gas flow. Although many past studies have demonstrated the effectiveness of PAC, the understanding of the mechanism as to how exactly plasma discharges enhance combustion is still limited. One of the reasons is the vastly different kinetic pathways that plasma discharges introduce. In this regard, the reduced electric field $E / N$, which is the electric field divided by the gas number density, is an important parameter governing the behavior of plasma discharges. $E / N$ is a scale of the energy that electrons gain from the electric field between collisions, and it characterizes how the electron energy is redistributed to heavy particles.

The value of $E / N$ controls the partitions of the electron energy among the DOF of the constituent atoms and molecules of the system. At different values of $E / N$, the electron energy is lost to different DOF with progressively higher energy levels being excited as $E / N$ increases [5]. These high-energy DOF may equilibrate with other DOF or among themselves relatively slowly, allowing for other kinetic processes to occur. In fact, vibrationally or electronically excited particles

sometimes demonstrate chemical reaction rates significantly higher than their ground-state 
counterparts [5] due to their high energy. The kinetics governing PAC can be conceptually summarized into a three step process: (1) the creation of high-energy species by electron-impact processes, (2) reactions of the high-energy species with other species, and (3) their subsequent influences on the overall oxidation mechanism.

The electron-impact processes themselves are relatively well understood, especially for common gases such as $\mathrm{Ar}, \mathrm{N}_{2}, \mathrm{O}_{2}$, or $\mathrm{H}_{2}$. For modeling purposes, databases of electron impact collision cross sections for a desired gas are readily available [6]. Using a Boltzmann equation solver (e.g., BOLSIG+ [7]), the electron energy distribution function (EEDF) can be obtained for a given temperature, mixture, and $E / N$. From the EEDF, the production rates of high-energy species can be determined. Such high-energy species may be roughly divided into four types: ground state radicals, electronically excited species, ions, and vibrationally excited species.

The ground state radicals, which include reactant fragments such as $\mathrm{O}$ or $\mathrm{H}$ atoms, are already incorporated in conventional combustion reaction mechanisms. Thus, their roles in fuel oxidation have been studied rigorously, particularly at high temperatures $(T>1000 \mathrm{~K})$ [8]. On the other hand, their role at lower temperatures has had less attention because the oxidation processes are too slow to make use of in practice due to low concentrations of active species and reaction barriers of tens of $\mathrm{kcal} / \mathrm{mol}$ with typical hydrocarbons. However, PAC opens new possibilities to oxidize fuels at lower temperatures, and provides new motivation to study low temperature radical kinetics. An example of such work is that of Uddi et al. [9], where they performed optical measurements of the $\mathrm{O}$ atom density in a plasma and concluded that the consumption of $\mathrm{O}$ atoms was much faster in a fuel/air mixture than in air alone. Sun et al. [10] extended the analysis of O atom reactions even further, and identified that the reaction chain is extended to produce $\mathrm{H}$ and $\mathrm{OH}$ radicals, which subsequently initiates the low temperature oxidation chemistry of fuels. 
With regards to electronically-excited species, the combustion enhancement effects of the singlet delta oxygen molecule $\mathrm{O}_{2}\left(a^{1} \Delta_{\mathrm{g}}\right)$ have had significant study. The introduction of singlet delta oxygen to combustion systems has produced higher flame speeds and shorter ignition delays, both experimentally [11] and numerically [12-14]. For $\mathrm{H}_{2} / \mathrm{O}_{2}$ systems, the enhancement has been described to take place through the chain branching step [12,14]:

$$
\mathrm{H}+\mathrm{O}_{2}\left(a^{1} \Delta_{\mathrm{g}}\right) \rightarrow \mathrm{O}+\mathrm{OH}
$$

which proceeds faster than its ground state counterpart:

$$
\mathrm{H}+\mathrm{O}_{2} \rightarrow \mathrm{O}+\mathrm{OH}
$$

More recently, the influence of singlet oxygen atom $\mathrm{O}\left({ }^{1} \mathrm{D}\right)$ has been studied by Popov [15] and shown to influence oxidation through its reaction with fuel molecules by rapid production of radicals, particularly at low temperatures where the reactions of the ground state $\mathrm{O}$ atoms are slow.

The rates of ion reactions (i.e., ion-molecule, ion-ion, or ion-electron) have been compiled in several forms [16-20]. However, their significance in contributing to fuel oxidation is generally minimal due to their small concentrations in weakly ionized plasmas.

While outside of the scope of the present study, vibrationally excited $\mathrm{H}_{2}$ molecules, $\mathrm{H}_{2}(v)$, may play an important role for ignition and combustion phenomena [5]. For a few reactions such as

$$
\mathrm{H}_{2}(v)+\mathrm{O} \rightarrow \mathrm{H}+\mathrm{OH}
$$

and

$$
\mathrm{H}_{2}(v)+\mathrm{OH} \rightarrow \mathrm{H}+\mathrm{H}_{2} \mathrm{O}
$$

$\mathrm{H}_{2}$ molecules at vibrational quantum number $v=1$ are known to have two to three orders of magnitude faster reaction rates than those at $v=0$. However, their implications on the overall oxidation process have not been investigated thoroughly due to modeling complexities associated with their consideration. Incorporating vibrationally excited molecules in a chemical kinetics model is quite challenging because the data necessary to construct a reasonably-validated reaction 
mechanism involving vibrational excitations are limited, and in many cases not available. Still, despite the challenge, there have been several studies which have incorporated vibrationally excited species in models of $\mathrm{H}_{2} / \mathrm{O}_{2}$ systems [21-23], and all agree that $\mathrm{H}_{2}(v)$ molecules are capable of accelerating the rate of radical generation and reducing ignition delays.

It should be evident that the range of different types of species and reactions involved in PAC systems can make the system quite complex to understand. Any attempt at a detailed kinetic analysis almost certainly requires some level of modeling analysis. PAC modeling studies have incorporated both zero-dimensional [23-25] and one-dimensional [26] formulations. Of these works, the one by Nagaraja et al. [26] was unique not only because of the dimensionality, but also because they investigated the cumulative effects on ignition caused by multiple discharges. Although the ability to simulate the chemical kinetics in a multi-discharge system is desirable, the analysis becomes more difficult than single-pulse systems.

In summary, investigations to gain systematic understanding of the chemical kinetics of PAC are limited, particularly compared to kinetic studies on high temperature hydrocarbon oxidation, and a greater effort is needed in order to develop the understanding necessary for optimized integration of PAC into practical systems. As part of these elementary efforts, this study presents modeling results of PAC in a nanosecond dielectric barrier discharge (DBD) plasma flow reactor (PFR) at various temperatures and atmospheric pressure. Also, implications of the results on the overall PAC process are discussed with the aid of a formal sensitivity analysis. Together with species profiles and reaction flux analysis, in-depth insight into the governing kinetics is presented, including rate-limiting steps, competing steps, and time scales of the different sub-categories of chemistry. The modeling efforts presented in this paper are based on the experimental conditions presented in Tsolas et al. [27], to which the readers are directed for comparisons between experimental and modeling results. 


\section{Numerical Framework}

\subsection{Modeling Concept and Governing Equations}

In this study, the chemical reactions in the PFR are simulated using a code with zerodimensional formulations, assuming that species concentrations and $E / N$ are only functions of time (time that a fluid particle experiences in the reactor, as described later). With this zero-dimensional treatment, the use of sensitivity analysis with a detailed chemical reaction mechanism on a system with multiple plasma discharges is enabled without a prohibitively high computational cost.

The model consists of a modified SENKIN module [28] from CHEMKIN III suite, coupled with ZDPlasKin [29] package that provides access to a Boltzmann equation solver, BOLSIG+ [7]. The governing equations are a system of ordinary differential equations (ODEs) describing mass (species), and electric charge conservation equations. This set of ODEs describes the timedependent chemical kinetics in DBD plasma reactors as an initial value problem.

The mass conservation of the species $i$ is written in terms of the mass fraction $Y_{i}$ as:

$$
\frac{\mathrm{d} Y_{i}}{\mathrm{~d} t}=v W_{i} \dot{\omega}_{i}
$$

where $v$ is the specific volume of the mixture, $\dot{\omega}_{i}$ is the molar production rate of the species $i$, and $W_{i}$ is the molecular weight of the species $i$. The production rates are calculated by the law of mass action, whereas the reverse rates are calculated using the forward reaction rate constants and equilibrium constants. The electric field inside the discharge gap $E_{\text {gap }}$ is calculated by charge conservation (Kirchhoff's law) applied to the equivalent circuit of the DBD plasma system as shown in Fig. 1:

$$
\frac{\mathrm{d} V_{\text {gap }}(t)}{\mathrm{d} t}=\left(1+\frac{2 l_{\mathrm{d}}}{\varepsilon L}\right)^{-1}\left(\frac{\mathrm{d} V_{\text {app }}(t)}{\mathrm{d} t}-\frac{2 l_{\mathrm{d}}}{\varepsilon_{0} \varepsilon} J_{\mathrm{d}}(t)\right),
$$




$$
E_{\text {gap }}(t)=\frac{V_{\text {gap }}(t)}{L}
$$

Here, $V_{\text {gap }}$ is the voltage across the discharge gap, $V_{\text {app }}$ is the voltage applied to the electrodes, $J_{\mathrm{d}}$ is the discharge current density, $L$ is the gap length, $l_{\mathrm{d}}$ is the thickness of the dielectric layer, $\varepsilon$ is the relative permittivity of the dielectric material, and $\varepsilon_{0}$ is the vacuum permittivity. The relation described in Eqn. (3) is only an approximation that assumes quasi-neutrality everywhere across the discharge gap. While the bulk of the plasma can, in fact, be treated to be quasi-neutral, this approximation ignores the formation of the sheath near the cathode. However, analysis in Adamovich et al. [30] showed that a sheath acts like an extra layer of capacitor, and its effect on the energy coupling to the plasma is weak if its quasi-steady-state thickness $l_{\mathrm{s}}^{\infty}$ is much less than $2 l_{\mathrm{d}} / \varepsilon$. In this study, $l_{\mathrm{s}}^{\infty}$ was found to be one to two orders of magnitude less than $2 l_{\mathrm{d}} / \varepsilon$ across all the conditions considered. Thus, the error estimation in the coupled energy due to this approximation is no more than $10 \%$.

The coupling between the system of ODEs and the Boltzmann equation is made by supplying BOLSIG+ with the temperature, the number density of each species, as well as the $E / N$ value given by $E_{\text {gap }}$ divided by the number density of the gas $N$,

$$
\frac{E}{N}=\frac{\left|E_{\text {gap }}\right|}{N}
$$

and then updating the parameters in the ODEs with the values provided by BOLSIG+. The feedback parameters are the reaction rate constants of the electron-impact reactions and the electron drift velocity $v_{\mathrm{dr}}$, which is used to calculate the discharge current density $J_{\mathrm{d}}$ as:

$$
J_{\mathrm{d}}=e n_{\mathrm{e}} v_{\mathrm{dr}}
$$

where $e$ is the elementary charge and $n_{\mathrm{e}}$ is the number density of the electrons. Note that $v_{\mathrm{dr}}$ has the same sign as $E_{\text {gap }}$. This formulation of the discharge current density neglects the contributions from 
the drift of ions because ion motilities are much smaller than electron mobility. BOLSIG+ is called and the parameters are updated every time step.

The time integration of the ODEs is handled by the DASAC [31] solver, which is adopted directly from SENKIN. This solver is also used to solve the associated sensitivity analysis equations for the normalized sensitivity coefficients $\tilde{S}_{i, j}$ :

$$
\tilde{S}_{i, j}=\frac{k_{j}}{X_{i}} \frac{\partial X_{i}}{\partial k_{j}}=\frac{\partial \ln X_{i}}{\partial \ln k_{j}} .
$$

Mathematically, these coefficients represent the fractional change in $X_{i}$, the mole fraction of the species $i$, caused by a fractional change of $k_{j}$, the rate coefficient of the reaction $j$. These coefficients can provide physical insight into the dynamics of the chemical system when coefficients are compared to one another. It is often informative to examine the sensitivity coefficients for the reaction products specifically, since their formation represents the progress of the overall reaction. When coefficients are compared in this manner, reactions with the highest sensitivities are considered to be the rate-limiting steps of the overall reaction $[32,33]$.

\section{$2.2 \quad \mathrm{H}_{2} / \mathrm{O}_{2} /$ Ar Plasma Oxidation Reaction Mechanism}

The chemical reaction mechanism employed within this work consists of 39 species and 424 reactions. The mechanism is derived from the HP-Mech/Plasma mechanism [34], which is an expansion of the basic $\mathrm{H}_{2} / \mathrm{O}_{2}$ mechanism originally developed by Burke et al. [35]. Additional reactions pertaining to ions and electronically excited species of $\mathrm{Ar}, \mathrm{O}_{2}$, and $\mathrm{O}$ are included. Vibrational excitations are neglected in the current version of the mechanism as the characteristic time of vibrational relaxation of $\mathrm{H}_{2}(v=1)$ through VT collisions with Ar [36] is at least two orders of magnitude shorter than the characteristic times of reactions (R3) and (R4) [37] over the range of conditions considered in this study. The complete reaction set and associated rate constants are tabulated in Supplementary Material 1. 
The model also includes the thermodynamic properties of all species to ensure consistent calculation of the reverse rate constants. The properties of most of the species in the present mechanism are taken from the database compiled by Burcat and Ruscic [38], while those of the electronically-excited species and ionic species not found in the database were estimated from the spectroscopic parameters using a statistical-mechanical approach outlined by Liu et al. [39]. The least square fit polynomial coefficients of the thermodynamic properties in CHEMKIN format are presented in Supplementary Material 2.

\subsection{Simulation Conditions}

The aforementioned numerical model is used to describe the physics and the chemistry of the PFR experiments conducted by Tsolas et al. [27], where the reactor assembly was placed inside an electric tube furnace that created a trapezoidal temperature profile along the reactor. The model only considers the $40-\mathrm{cm}$ plateau (isothermal) region in the middle, of which the first $5 \mathrm{~cm}$ is the electrode assembly that generates the plasma. The temperature ramps on both sides of the plateau region are not included. When the furnace temperature is below the second explosion limit, the simulation results shown later suggest that the chemical reactions are almost frozen outside of the plasma region even in the isothermal region where the temperature is the highest, and by extension, the reaction rates in the temperature ramp region are even slower. The flow reactor is modeled as a plug flow reactor, where the assumption is that the time evolutions of the species in a fluid element that travels downstream with an average flow velocity $U$ is simulated. The initial composition is fixed at $2000 \mathrm{ppm} \mathrm{H}_{2}$ and $3000 \mathrm{ppm} \mathrm{O}_{2}$ balanced in Ar, and multiple cases are considered with different initial temperatures between $474 \mathrm{~K}$ and $1008 \mathrm{~K}$. As the mass flow rate of the gas is fixed for all cases, the average residence time of a fluid element within the reactor varies with the furnace temperature, $T$ (in kelvin). The average residence time of a fluid element traveling through the 40$\mathrm{cm}$ isothermal region is $409.5 / T$ seconds, of which the first $56.7 / T$ seconds corresponds to the $5-\mathrm{cm}$ 
plasma region where repetitive discharges are applied. The physical parameters of the reactor are set to be $L=7 \mathrm{~mm}, l_{\mathrm{d}}=2.3 \mathrm{~mm}$, and $\varepsilon=5.26(1.0 \mathrm{~mm}$ MACOR and $1.3 \mathrm{~mm}$ quartz). The voltage pulses applied to the electrodes are modeled as Gaussian pulses with a peak voltage of $10 \mathrm{kV}$ and FWHM of 83 ns (Fig. 2). All the results presented here are from the simulations performed with isobaric and isothermal conditions, as the primary intention of this paper is to study the pure kinetics by decoupling them from exothermic (or endothermic) effects. Simulations with isobaric and adiabatic conditions (with the addition of the energy conservation equation) were performed for reference, however, and the temperature changes were found to be less than $35 \mathrm{~K}$ at all initial temperatures, owing to the use of a dilute mixture.

\section{Results and Discussions}

\subsection{Single Discharge at Low Temperature}

To simplify any forthcoming discussion, a single discharge system is first considered and analyzed. The conditions were set to replicate the experiments of Tsolas et al. [27], with the exception that only one high-voltage pulse is applied. The initial mixture of the gas is set at $668 \mathrm{~K}$ and $1 \mathrm{~atm}$. This condition is well below the second explosion limit $(878 \mathrm{~K}$ at $1 \mathrm{~atm}$ as determined from the model) and thus called "low temperature."

Figure 3 shows the simulated behavior of the $E / N$ value and the species evolution when a single Gaussian voltage pulse is applied to the initial mixture. The voltage pulse peaks at $t=100 \mathrm{~ns}$ while breakdown occurs a few ns prior. The maximum $E / N$ before the breakdown is $110 \mathrm{Td}$. After the breakdown, electric charges are built up on the surfaces of the dielectric materials by the electric current in the plasma, and the gap electric field is rapidly reduced. A second peak of $E / N$ follows with a maximum value of $3.2 \mathrm{Td}$ (secondary discharge), which is caused by the change in the sign of the time derivative of the applied voltage. During this very short breakdown process, the electron 
energies are transferred to atoms and molecules through collisions. The important electron-impact process on the species evolutions shown in Fig. 3 is the excitation of an Ar atom to its $4 s$ metastable state $\mathrm{Ar}^{*}{ }^{\mathrm{m}}$ :

$$
\mathrm{e}^{-}+\mathrm{Ar} \rightarrow \mathrm{Ar}^{*} \mathrm{~m}+\mathrm{e}^{-}
$$

This electronic excitation step of argon is the dominant path for electron energy losses for $E / N$ above $10 \mathrm{Td}$. These metastable argon atoms are efficiently quenched through collisions with diatomic or polyatomic molecules in the gas, and such collisions with $\mathrm{H}_{2}$ or $\mathrm{O}_{2}$ molecules predominantly result in dissociation $[40,41]$. These dissociation processes are the major contributor of $\mathrm{H}$ and $\mathrm{O}$ atoms in the gas before $t=10^{-6} \mathrm{~s}$. In turn, these ground-state atoms subsequently drive the conventional reactions found in the $\mathrm{H}_{2} / \mathrm{O}_{2}$ mechanism, which contribute the most to the oxidation of the fuel on a timescale of $\sim 0.1 \mathrm{~ms}$ and longer. The $\mathrm{H}$ atoms formed by $\mathrm{H}_{2}$ dissociation start the fuel oxidation sequence with the production of $\mathrm{HO}_{2}$ through

$$
\mathrm{H}+\mathrm{O}_{2}(+\mathrm{M}) \rightarrow \mathrm{HO}_{2}(+\mathrm{M})
$$

The majority of $\mathrm{HO}_{2}$ formed by this reaction is then converted to $\mathrm{OH}$ either by $\mathrm{O}$ or $\mathrm{H}$ :

$$
\begin{gathered}
\mathrm{HO}_{2}+\mathrm{O} \rightarrow \mathrm{O}_{2}+\mathrm{OH} \\
\mathrm{HO}_{2}+\mathrm{H} \rightarrow 2 \mathrm{OH}
\end{gathered}
$$

and finally, $\mathrm{OH}$ reacts with $\mathrm{H}_{2}$ to produce $\mathrm{H}_{2} \mathrm{O}$, the final product:

$$
\mathrm{H}_{2}+\mathrm{OH} \rightarrow \mathrm{H}_{2} \mathrm{O}+\mathrm{H}
$$

The majority of the $\mathrm{O}$ atoms formed from $\mathrm{O}_{2}$ dissociation are consumed through either the termination step (R7) or the branching step

$$
\mathrm{O}+\mathrm{H}_{2} \rightarrow \mathrm{H}+\mathrm{OH}
$$

$\mathrm{H}$ and $\mathrm{OH}$ radicals produced by reactions $(\mathrm{R} 7)$ and (R10) then join the radical pool that drives reactions (R6), (R8), and (R9). 
Detailed path flux analysis of the oxidation mechanism reveals that the reactions of $\mathrm{HO}_{2}$ play a very important role on the kinetics of $\mathrm{H}, \mathrm{OH}$, and $\mathrm{O}$ radicals, and hence on the $\mathrm{H}_{2}$ oxidation. The $\mathrm{HO}_{2}$ consumption routes, integrated over a time period of $10^{-2} \mathrm{~s}$ corresponding to an approximate lifetime of $\mathrm{H}, \mathrm{OH}$, and $\mathrm{O}$ radicals as seen in Fig. 3, consisted of the following reactions and percentages of total consumption:

$$
\begin{gathered}
\mathrm{HO}_{2}+\mathrm{O} \rightarrow \mathrm{O}_{2}+\mathrm{OH}, 32 \% ; \\
\mathrm{HO}_{2}+\mathrm{H} \rightarrow 2 \mathrm{OH}, 41 \% ; \\
\mathrm{HO}_{2}+\mathrm{OH} \rightarrow \mathrm{H}_{2} \mathrm{O}+\mathrm{O}_{2}, 10 \% ; \\
\mathrm{HO}_{2}+\mathrm{H} \rightarrow \mathrm{H}_{2}+\mathrm{O}_{2}, 5 \% ; \\
\mathrm{HO}_{2}+\mathrm{H} \rightarrow \mathrm{H}_{2} \mathrm{O}+\mathrm{O}\left({ }^{1} \mathrm{D}\right), 5 \% ; \\
2 \mathrm{HO}_{2} \rightarrow \mathrm{H}_{2} \mathrm{O}_{2}+\mathrm{O}_{2}, 7 \% .
\end{gathered}
$$

Of these six reactions, (R8) is the only step that is chain propagating; all other reactions are chain terminating steps that lead to the depletion of $\mathrm{H}, \mathrm{OH}$, and $\mathrm{O}$ radicals. Thus, as the $\mathrm{HO}_{2}$ concentration builds up, the rate of radical loss from the system is accelerated. The formation of $\mathrm{H}_{2} \mathrm{O}_{2}$ from reaction (R14), while being slower than other reactions, contributes to the eventual removal of $\mathrm{HO}_{2}$ from the mixture after other radicals are depleted.

Examining the reactions from (R6) through (R14), it is interesting to point out that reaction (R13), which accounts for only $5 \%$ of the $\mathrm{HO}_{2}$ consumption, is the only producer of $\mathrm{O}$ atoms through thermal reactions ${ }^{\dagger}$. This is in sharp contrast with the large yield of $\mathrm{OH}$ from $\mathrm{HO}_{2}$ by reactions (R7) and (R8), which subsequently react to form $\mathrm{H}$ and $\mathrm{H}_{2} \mathrm{O}$ from reaction (R9). The small yield of $\mathrm{O}$ atoms in a low temperature system also results from the slow rate of their major producer usually found active in a high temperature $\mathrm{H}_{2} / \mathrm{O}_{2}$ system, i.e., the chain branching step

\footnotetext{
${ }^{\dagger}$ The majority of $\mathrm{O}\left({ }^{1} \mathrm{D}\right)$ is collisionally quenched to the ground state in the present system. See later discussions.
} 
At low temperatures, this step is slow due to its endothermicity [42], making its participation in the overall oxidation process of minimal importance. It is in fact driven backwards by the superequilibrium concentrations of $\mathrm{O}$ and $\mathrm{OH}$ under the present condition. The low yield of $\mathrm{O}$ atoms from the thermal reactions essentially eliminates the exponential growth characteristics of the system that would otherwise facilitate reaction (R10) at high temperatures. This also makes competing reaction (R6) to become both a necessary and major consumer of $\mathrm{H}$ atoms, allowing the $\mathrm{HO}_{2}$ chemistry to govern the $\mathrm{H}_{2}$ oxidation mechanism in the low-temperature plasma system.

The sensitivity analysis results agree with the aforementioned discussion. Figure 4 shows the time evolution of sensitivity coefficients for the mole fraction of the product species $\mathrm{H}_{2} \mathrm{O}$. The sensitivity plots reveal three different reaction schemes: two "short time scale" schemes that form a small quantity of $\mathrm{H}_{2} \mathrm{O}$ rapidly and a "long time scale" scheme that forms the majority of $\mathrm{H}_{2} \mathrm{O}$ more slowly. The first scheme involves the reactions of negative ions, $\mathrm{O}^{-}$, and $\mathrm{O}_{2}^{-}$. Shortly after the breakdown, the electrons produced during the breakdown facilitates the rapid formation of $\sim 10^{-2}$ ppm of $\mathrm{H}_{2} \mathrm{O}$ between $10^{-7} \mathrm{~s}$ and $10^{-5} \mathrm{~s}$ either by

$$
\begin{gathered}
\mathrm{e}^{-}+\mathrm{O}_{2} \rightarrow \mathrm{O}^{-}+\mathrm{O} \\
\mathrm{O}^{-}+\mathrm{H}_{2} \rightarrow \mathrm{e}^{-}+\mathrm{H}_{2} \mathrm{O}
\end{gathered}
$$

or

$$
\begin{gathered}
\mathrm{e}^{-}+\mathrm{O}_{2}+\mathrm{M} / \mathrm{O}_{2} \rightarrow \mathrm{O}_{2}^{-}+\mathrm{M} / \mathrm{O}_{2} \\
\mathrm{O}_{2}^{-}+\mathrm{O} \rightarrow \mathrm{O}^{-}+\mathrm{O}_{2} \\
\mathrm{O}^{-}+\mathrm{H}_{2} \rightarrow \mathrm{e}^{-}+\mathrm{H}_{2} \mathrm{O}
\end{gathered}
$$

before electrons are depleted through recombination with positive ions. While being rate-limited by formation steps of negative ions (i.e., reactions (R15) and (R17)), there are no other reactions that 
compete with this scheme. The second scheme involves the reactions of $\mathrm{O}\left({ }^{1} \mathrm{D}\right)$ atoms that are predominantly produced through dissociation of $\mathrm{O}_{2}$ molecules through collisions with $\mathrm{Ar}^{* \mathrm{~m}}$.

$$
\begin{gathered}
\mathrm{Ar}^{*}+\mathrm{O}_{2} \rightarrow \mathrm{O}+\mathrm{O}\left({ }^{1} \mathrm{D}\right) \\
\mathrm{O}\left({ }^{1} \mathrm{D}\right)+\mathrm{H}_{2} \rightarrow \mathrm{OH}+\mathrm{H} \\
\mathrm{H}_{2}+\mathrm{OH} \rightarrow \mathrm{H}_{2} \mathrm{O}+\mathrm{H}
\end{gathered}
$$

Rapid formation of $\mathrm{OH}$ radicals before $10^{-6}$ s occurs through reaction (R20) and the amount of $\mathrm{H}_{2} \mathrm{O}$ formation from this scheme is comparable to the negative ion scheme. This scheme has alternate paths for $\mathrm{Ar}^{* \mathrm{~m}}$ and $\mathrm{O}\left({ }^{1} \mathrm{D}\right)$ clearly seen in Fig. 4a, i.e.,

$$
\mathrm{Ar}^{* \mathrm{~m}}+\mathrm{O}_{2} \rightarrow 2 \mathrm{O}
$$

and

$$
\mathrm{O}\left({ }^{1} \mathrm{D}\right)+\mathrm{Ar} \rightarrow \mathrm{O}+\mathrm{Ar}
$$

competing with reactions (R19) and (R20), respectively. However, the impact of these two schemes is limited to "short time scales." Although they form $\mathrm{H}_{2} \mathrm{O}$ very rapidly, the quantity of formation is much lesser than the "long time scale" scheme consisting of reactions (R5) through (R10), which is driven by molecular dissociation and $\mathrm{HO}_{2}$ chemistry as explained before. At time scales longer than $10^{-4} \mathrm{~s}$ in Fig. $4 \mathrm{~b}$, the large positive sensitivity coefficients are associated with reactions (R5), (R8), (R9), and (R10). The negative coefficients are associated with the $\mathrm{HO}_{2}$ production step (R6) as well as the $\mathrm{HO}_{2}$ consumption steps other than reaction (R8), i.e.,

$$
\begin{gathered}
\mathrm{HO}_{2}+\mathrm{O} \rightarrow \mathrm{O}_{2}+\mathrm{OH} \\
\mathrm{HO}_{2}+\mathrm{OH} \rightarrow \mathrm{H}_{2} \mathrm{O}+\mathrm{O}_{2} \\
\mathrm{HO}_{2}+\mathrm{H} \rightarrow \mathrm{H}_{2}+\mathrm{O}_{2} \\
\mathrm{HO}_{2}+\mathrm{H} \rightarrow \mathrm{H}_{2} \mathrm{O}+\mathrm{O}\left({ }^{1} \mathrm{D}\right) \\
2 \mathrm{HO}_{2} \rightarrow \mathrm{H}_{2} \mathrm{O}_{2}+\mathrm{O}_{2}
\end{gathered}
$$


although the sensitivity coefficients of reactions (R13) and (R14) are omitted from the figure due to their small magnitudes. The sensitivity coefficient associated with reaction (R6) behaves rather interestingly, because of the mixed role of $\mathrm{HO}_{2}$. Its value is positive initially because of the necessity of $\mathrm{HO}_{2}$ production on fuel oxidation facilitated through reaction (R8). It then turns negative at $10^{-3} \mathrm{~s}$ when reactions $(\mathrm{R} 7),(\mathrm{R} 11)$, and (R12), which are chain termination steps, become competitive with reaction (R8) for $\mathrm{HO}_{2}$. Reaction (R8) is the "desired" $\mathrm{HO}_{2}$ consumption path because it is the only chain propagation step.

As discussed above, formation of $\mathrm{Ar}^{*}{ }^{* \mathrm{~m}}$ via reaction (R5) is one of the steps to which the system is the most sensitive because $\mathrm{Ar}^{* \mathrm{~m}}$ produces $\mathrm{H}$ and $\mathrm{O}$ atoms efficiently by dissociation. However, interestingly, the dissociation steps themselves are not among those with the highest sensitivities, except for the competition between the production of the ground-state $\mathrm{O}$ atom via reaction $(\mathrm{R} 21)$ and the excited-state $\mathrm{O}\left({ }^{1} \mathrm{D}\right)$ atom via reaction $(\mathrm{R} 19)$ during short time scales. There are two reasons behind this, and the first one is the absence of a process that can quench $\mathrm{Ar}^{* \mathrm{~m}}$ as efficiently as the dissociation processes involving reactants $\mathrm{H}_{2}$ and $\mathrm{O}_{2}$. Because of the dilute characteristics of the mixture with more than $99 \% \mathrm{Ar}$ in the mixture, $\mathrm{Ar}$ is naturally the most probable collision partner in the system. However, collisional quenching of $\mathrm{Ar}^{{ }^{* \mathrm{~m}}}$ with ground state Ar is four orders of magnitude slower than that with $\mathrm{H}_{2}$ or $\mathrm{O}_{2}$ (see Supplementary Material 1 for rates). Therefore, collisions of $\mathrm{Ar}^{* \mathrm{~m}}$ with the initial reactant molecules of $\mathrm{H}_{2}$ and $\mathrm{O}_{2}$ are still the major consumption paths of $\mathrm{Ar}^{{ }^{*} \mathrm{~m}}$ even though their mole fractions are only of the order of $10^{3} \mathrm{ppm}$. The second reason is that dissociation processes of both $\mathrm{H}_{2}$ and $\mathrm{O}_{2}$ contribute to the oxidation process. Microscopically, they are competing with each other for the removal of $\mathrm{Ar}^{* \mathrm{~m}}$, while macroscopically as far as the overall oxidation process is concerned, they both achieve almost the same result. The second argument pointed out here is expected to be a unique feature of an $\mathrm{H}_{2} / \mathrm{O}_{2} / \mathrm{Ar}$ system where $\mathrm{H}_{2} \mathrm{O}$ is the only major product and the major molecular species in the 
system are both reactants. The product distribution from collisions of $\mathrm{Ar}^{{ }^{*} \mathrm{~m}}$ with other species is expected to carry much more importance in other systems, such as ones with more complex hydrocarbon fuels.

\subsection{Repetitive Discharges at Low Temperature}

In this section, the single discharge analysis is extended to the analysis of a multi-discharge system that reflects the experimental conditions of [27] more appropriately. Figure 5 shows the time evolution of species profiles simulated in the isothermal region of the reactor at $T=668 \mathrm{~K}$ when the repetitive voltage pulses are applied at a rate of $1 \mathrm{kHz}$. The maximum $E / N$ remained nearly constant pulse to pulse. The oxidation of fuel proceeds almost linearly with time within the plasma region, which is the first $85 \mathrm{~ms}$ indicated by the gray region in the plots. This prediction is directly equivalent to the trends observed in the experiments, where the plasma discharge perturbations are applied at the beginning of the isothermal region. The simulations demonstrate that at this particular reactor temperature the extent of the reaction is confined to the plasma discharge region with little reaction continuing upon exiting. In Fig. 5b-d, the evolution of radical species are tracked through the plasma discharge. Here, it can be seen that these species are directly coupled to the plasma perturbations, continually being formed and consumed for every single discharge pulse. The slight change in behaviors of the radical species observed near $75 \mathrm{~ms}$ is caused by the reduction of $E / N$ during the secondary discharges. This results from the progressive increase in electron drift velocity at values of $E / N$ on the order of $0.1 \mathrm{Td}$ and above as $\mathrm{H}_{2} \mathrm{O}$ accumulates in the mixture, which was reported previously in air $[43,44]$ and also verified with BOLSIG+ [7] calculations for the present results. The predicted profiles of both major and radical species indicate the lack of chain-branching chemistry, which is also supported by the reaction flux plots of $\mathrm{H}_{2} \mathrm{O}$ and $\mathrm{OH}$ shown in Fig. 6. The dominant $\mathrm{H}_{2} \mathrm{O}$ formation step is reaction (R9), which is also the dominant consumption step of $\mathrm{OH}$. Hydroxyl radicals are formed by reactions (R8), (R7), and (R10), in the order of significance. 
Figure 7 shows the normalized sensitivity coefficients for $\mathrm{H}_{2} \mathrm{O}$ and $\mathrm{OH}$ in the plasma region. The sensitivity coefficient of the ionization step

$$
\mathrm{e}^{-}+\mathrm{Ar} \rightarrow \mathrm{Ar}^{+}+2 \mathrm{e}^{-}
$$

rises and falls quite drastically. The close coupling of the sensitivity coefficient to the breakdown makes the effects of perturbing this reaction very complicated over multiple discharges, and the sensitivity coefficient represented by only a local first order derivative of mole fraction, without accounting for higher order effects, carries much less significance. A brute force sensitivity coefficient for reaction (R23) (which takes into account the higher order effects) shows negative values overall. One notable difference between the sensitivity coefficient plots for $\mathrm{H}_{2} \mathrm{O}$ and $\mathrm{OH}$ is that the former are smooth while the latter oscillate. This is a result largely from the normalization process, Eqn. (6), where $\mathrm{H}_{2} \mathrm{O}$ is a final product that builds up with time rather smoothly, while $\mathrm{OH}$ is an intermediate species whose mole fraction fluctuation with every discharge is significant compared to the $\mathrm{OH}$ absolute value. An interesting observation for the $\mathrm{H}_{2} \mathrm{O}$ sensitivity coefficients is that the reactions with large absolute values of sensitivity coefficients in Fig. 7a are very similar to the ones of importance during the long time scale shown in Fig. 4. The $\mathrm{OH}$ mole fraction is sensitive to reactions similar to those found sensitive for $\mathrm{H}_{2} \mathrm{O}$, indicating a close coupling with the $\mathrm{H}_{2} \mathrm{O}$ formation.

Figure 8 shows the change in the normalized sensitivity coefficients for $\mathrm{H}_{2} \mathrm{O}$ when the pulse repetition rate of the discharges is varied between $1 \mathrm{kHz}, 3 \mathrm{kHz}$, and $5 \mathrm{kHz}$. As the pulse repetition rate increases, the magnitudes of the coefficients associated with reactions (R5), (R8), and (R6) decline more than the coefficients of other reactions. These three reactions are the steps responsible for production and consumption of $\mathrm{H}$ atoms. In contrast, the coefficients associated $\mathrm{OH}$ consumption steps, i.e., reactions (R2) and (R9), show an increase in magnitude with the pulse 
repetition rate. These results suggest a shift in the rate-limiting process of the reaction chain from reactions of $\mathrm{H}$ atoms to those of $\mathrm{OH}$.

\subsection{Kinetics at High Temperature}

At temperatures above the second explosion limit, the thermal chain branching factor is greater than unity, and the role of the plasma is presented here for a similar mixture composition and pressure, but a temperature of $921 \mathrm{~K}$. Figure 9 shows the simulated behavior of $E / N$ and the species evolution when a single Gaussian voltage pulse is applied to the initial mixture. The maximum $E / N$ before the breakdown is 135 Td. Comparing Fig. 9 with Fig. 3, almost identical reaction profiles are predicted up to around $10^{-5} \mathrm{~s}$, showing the amounts of $\mathrm{O}$ and $\mathrm{H}$ atom formation to be on the order of $1 \mathrm{ppm}$ due to dissociation of the initial reactants. However, instead of the radical concentrations declining after this time, the reactions shift to overall chain-branching characterized by an exponential growth in the radical concentrations peaking around $10^{-2} \mathrm{~s}$. The plasma discharge created sufficient radicals to initiate the explosive character almost immediately, and the need for any further thermal radical buildup is unnecessary. Just as in the low temperature case, molecular dissociation was found to be responsible for the onset of radical growth.

Figure 10 compares the reactant and product species profiles for simulations with no plasma application (thermal), one discharge at the beginning of the reaction, and multiple discharges during the reaction at a pulse repetition rate of $1 \mathrm{kHz}$. A drastic reduction in the ignition delay, by about $35 \mathrm{~ms}$, is predicted even with one discharge compared to the thermal case, but applying multiple discharges only further reduced the ignition delay by about $1 \mathrm{~ms}$ from the singledischarge case. Since the curves of the profiles are similar to each other after its ignition delay period, thermal chain-branching reactions appear to dominate the oxidation process during fuel consumption, even when multiple plasma discharges are applied. The dominance of the chainbranching kinetics is confirmed by the sensitivity coefficients shown in Fig. 11, where the most 
sensitive reactions and the sensitivity coefficient profiles are similar to those found for high temperature thermal chain branched chemistry (see, for example, Mueller et al. [45]).

\subsection{Dependence of Kinetics on Temperature}

In Ref. [27], the plasma flow reactor experiments were performed for a wide range of temperatures where the extent of reaction was monitored by measuring the $\mathrm{H}_{2}$ and $\mathrm{O}_{2}$ species concentrations at the reactor outlet for a fixed mass flow rate. The simulations of these experiments are presented in Fig. 12. The increase in reactor temperature produces a faster plasma assisted reaction and higher $E / N$ in the plasma region, resulting in more oxidation which agrees with the trends observed in the experiments [27].

Figure 13 shows the temperature dependence of the normalized sensitivity coefficients of the $\mathrm{H}_{2} \mathrm{O}$ mole fraction at the reactor exit. The sensitivity coefficients approach zero above the second explosion limit $\left(878 \mathrm{~K}\right.$ ) because almost all the $\mathrm{H}_{2}$ is oxidized upstream before reaching the exit. As a consequence, the reactions become microscopically balanced as equilibrium is approached, and the forward and backward rate constants of each reaction have equal importance. Focusing on the temperature dependence of the sensitivity coefficients, the coefficients associated with reaction (R7) and reaction (R2) are found to have positive values at some temperatures and negative values at others. Reaction ( $\mathrm{R} 7)$, a $\mathrm{HO}_{2}$ consumption step, has positive sensitivity coefficients below $\sim 550 \mathrm{~K}$ and negative coefficients above it. This behavior arises from its direct competition with reaction (R8) as they both form $\mathrm{OH}$ from $\mathrm{HO}_{2}$. At temperatures below $\sim 550 \mathrm{~K}$, despite its chain-terminating nature, reaction (R7) actually produces $\mathrm{OH}$ faster than reaction (R8), thus making its sensitivity coefficient positive. As temperature increases, the $\mathrm{OH}$ production rate by reaction (R8) overtakes that by reaction (R7) and the sensitivity coefficient for reaction (R7) becomes negative above $\sim 550 \mathrm{~K}$. The sensitivity coefficient of reaction (R2), on the other hand, change sign at $\sim 720 \mathrm{~K}$ from negative at low temperatures to positive at high temperatures. This 
change in coefficient sign is an interesting result because chain branching steps usually have the largest positive sensitivity coefficient in a conventional chain-branching system [45]. The negative values at low temperatures arise from the fact that the superequilibrium radical concentrations drive reaction (R2) backwards, effectively making it a chain-termination step.

\subsection{Kinetics of $\mathrm{O}_{2}\left(a^{1} \Delta_{\mathrm{g}}\right)$ and $\mathrm{O}\left({ }^{1} \mathrm{D}\right)$}

Despite being proposed to be important by many researchers, electronic excitation of $\mathrm{O}_{2}$ by the plasma was not identified to play a significant role for the conditions of the present study. The ineffectiveness of $\mathrm{O}_{2}\left(a^{1} \Delta_{\mathrm{g}}\right)$ can be attributed to its small concentration $\left(\left[\mathrm{O}_{2}\left(a^{1} \Delta_{\mathrm{g}}\right)\right] /\left[\mathrm{O}_{2}\right] \approx 10^{-5}\right.$ to $10^{-}$ $\left.{ }^{4}\right)$ and the large concentration of $\mathrm{HO}_{2}$ that quenches $\mathrm{O}_{2}\left(a^{1} \Delta_{\mathrm{g}}\right)$ to ground state $\mathrm{O}_{2}$ at low temperatures. The former is likely a result of the abundance of $\mathrm{Ar}$ in the mixture, which makes Ar the most probable collision partner of electrons. If $\mathrm{Ar}$ is excited by an electron, the energy is high such that subsequent collisions with $\mathrm{O}_{2}$ predominantly result in dissociation instead of excitation (the energy of $\mathrm{O}_{2}\left(a^{1} \Delta_{\mathrm{g}}\right)$ is $0.98 \mathrm{eV}$ while the first excited state of $\mathrm{Ar}$ is $\left.11.55 \mathrm{eV}\right) . \mathrm{O}_{2}\left(a^{1} \Delta_{\mathrm{g}}\right)$ in the present system results from direct excitation by a small fraction of electrons, collisional quenching of the higher states, and the energy transfer from $\mathrm{O}\left({ }^{1} \mathrm{D}\right)$ :

$$
\mathrm{O}\left({ }^{1} \mathrm{D}\right)+\mathrm{O}_{2} \rightarrow \mathrm{O}+\mathrm{O}_{2}\left(a^{1} \Delta_{\mathrm{g}}, b^{1} \Sigma_{\mathrm{g}}^{+}\right)
$$

Together with the relative importance of molecular dissociations as a means of oxidation enhancement, the same conclusion drawn by Popov [14] can be made here regarding the difficulty to observe an influence of $\mathrm{O}_{2}\left(a^{1} \Delta_{\mathrm{g}}\right)$ when the plasma also produces atomic species by dissociation.

On the other hand, the reactions of $\mathrm{O}\left({ }^{1} \mathrm{D}\right)$ are shown to rapidly produce $\mathrm{OH}$ radicals during the time scale of $10^{-6} \mathrm{~s}$, contributing to $\mathrm{H}_{2}$ oxidation. Unlike $\mathrm{O}_{2}\left(a^{1} \Delta_{\mathrm{g}}\right)$ molecules, $\mathrm{O}\left({ }^{1} \mathrm{D}\right)$ atoms are produced rather effectively in a plasma in Ar-abundant mixtures because it is formed through collisions between $\mathrm{Ar}^{*}$ and $\mathrm{O}_{2}$ [46]. For the present conditions, the consumption steps of $\mathrm{O}\left({ }^{1} \mathrm{D}\right)$ are, in the order of significance: 


$$
\begin{gathered}
\mathrm{O}\left({ }^{1} \mathrm{D}\right)+\mathrm{Ar} \rightarrow \mathrm{O}+\mathrm{Ar} \\
\mathrm{O}\left({ }^{1} \mathrm{D}\right)+\mathrm{H}_{2} \rightarrow \mathrm{OH}+\mathrm{H} \\
\mathrm{O}\left({ }^{1} \mathrm{D}\right)+\mathrm{O}_{2} \rightarrow \mathrm{O}+\mathrm{O}_{2}\left(X^{3} \Sigma_{\mathrm{g}}^{-}, a^{1} \Delta_{\mathrm{g}}, b^{1} \Sigma_{\mathrm{g}}^{+}\right) \\
\mathrm{O}\left({ }^{1} \mathrm{D}\right)+\mathrm{H}_{2} \mathrm{O} \rightarrow 2 \mathrm{OH} .
\end{gathered}
$$

More than $70 \%$ of $\mathrm{O}\left({ }^{1} \mathrm{D}\right)$ atoms are quenched by $\mathrm{Ar}(\mathrm{R} 22)$, diminishing the branching effects of other paths that could have otherwise enhanced the overall $\mathrm{H}_{2}$ oxidation. More flux of $\mathrm{O}\left({ }^{1} \mathrm{D}\right)$ through reactions (R20), (R24), and (R25) in a less-dilute mixture could have made appreciable contributions at temperatures below the second explosion limit where, as discussed in the previous sections, the amount of radicals produced by the plasma is closely related to the oxidation rate. For example, using the current reaction rate expressions at $T=668 \mathrm{~K}$, having about $[\mathrm{Ar}]:\left[\mathrm{H}_{2}\right]=108: 1$ will make the reaction flux of the branching reaction (R20) comparable to that of the electronic quenching reaction (R22). In contrast, those effects would have been minimal above the second explosion limit where the conventional ground state chain branching kinetics is responsible for the majority of the oxidation. Since the plasma already produces more than sufficient seed radicals to trigger the ignition without delay, producing even more radicals through $\mathrm{O}\left({ }^{1} \mathrm{D}\right)$ reactions would not have made an appreciable difference.

Comparison of the consumption steps of $\mathrm{O}\left({ }^{1} \mathrm{D}\right)$ with those of ground state $\mathrm{O}$ poses a question on a possibly missing reaction with $\mathrm{HO}_{2}$. For the ground state $\mathrm{O}$, reaction (R7) is in fact one of the major consumption paths below the second explosion limit. No such reaction is included in the mechanism for the excited state $\mathrm{O}\left({ }^{1} \mathrm{D}\right)$, but if it actually exists, it could become an important radical termination step that competes with the existing reactions discussed above. No discussion about this reaction was found through an extensive literature survey, except p. 387 of Banks and Kockarts [47] mentions that experimental evidence does not rule out such a reaction which could have zero activation energy (similarly to reaction (R7)) and proceed at a rate similar to the reactions 
of $\mathrm{O}\left({ }^{1} \mathrm{D}\right)$ with $\mathrm{H}_{2}(\mathrm{R} 20)$ or $\mathrm{O}_{3}$. Although the existence of the reaction $\mathrm{O}\left({ }^{1} \mathrm{D}\right)+\mathrm{HO}_{2}$ remains an open question, missing this reaction would not have made a difference to the predictions of the present system as the enhancement effect of $\mathrm{O}\left({ }^{1} \mathrm{D}\right)$ kinetics is already diminished by the abundance of $\mathrm{Ar}$ and the reaction in question is likely to only weaken it further.

\section{Conclusions}

A new numerical code and a reaction mechanism that simulates the chemical kinetics in nanosecond DBD plasma was developed. The code was equipped with sensitivity analysis capabilities, aiming to provide deeper insight into the chemical kinetics than analysis of species profiles or reaction fluxes can provide alone.

Simulations coupled with sensitivity analysis were conducted to study and analyze the kinetics of an $\mathrm{H}_{2} / \mathrm{O}_{2} /$ Ar system excited by non-equilibrium plasma discharges. The simulations were performed at atmospheric pressure for a temperature range that would cover the kinetics both below and above the second explosion limit. For all conditions, dissociation of $\mathrm{H}_{2}$ and $\mathrm{O}_{2}$ molecules through their collisions with metastable $\mathrm{Ar}^{*} \mathrm{~m}$ produce the radicals that initiate the oxidation process. At temperatures below the second explosion limit, the plasma discharges were found to drive the fuel oxidation through a straight-chain sequence of the ground-state reactions, driven by molecular dissociation. An important part of the straight-chain reaction sequence is the kinetics of $\mathrm{HO}_{2}$, an inevitable intermediate species below the second explosion limit. It was found that the amount of $\mathrm{OH}$ radicals produced from $\mathrm{HO}_{2}$ affects the overall rate of $\mathrm{H}_{2}$ oxidation significantly. However, the $\mathrm{HO}_{2}$ chemistry itself has a chain terminating nature and depletes the radicals as $\mathrm{HO}_{2}$ builds up. At temperatures above the second limit, the molecular dissociation by the plasma produced more than sufficient amounts of radicals to trigger the chain branching kinetics significantly reducing its ignition delay. Varying the pulse repetition rate of the plasma discharges between 1 and $5 \mathrm{kHz}$ 
changed the rate-limiting steps of the mechanism. As the pulse rate was increased, the rate-limiting steps shifted from reactions of $\mathrm{H}$ atoms to those of $\mathrm{OH}$.

In addition, the findings are further analyzed to discuss the implications to other systems. It was suggested that in some systems, the fate of $\mathrm{Ar}^{* \mathrm{~m}}$ as well as the kinetics of $\mathrm{O}_{2}\left(a^{1} \Delta_{\mathrm{g}}\right)$ and $\mathrm{O}\left({ }^{1} \mathrm{D}\right)$ may carry much more importance.

\section{Acknowledgements}

This work was supported by the MURI program of the US Air Force Office of Scientific Research (FA9550-09-0602) with Dr. Chiping Li as technical monitor. K.T. is thankful for the financial support by the Long-Term Study Abroad Scholarship of Japan Student Services Organization. The authors also thank Dr. Igor Adamovich for helpful discussions on the modeling of PAC.

\section{References}

[1] C. Segal, The Scramjet Engine: Processes and Characteristics, Cambridge University Press, Cambridge, New York, 2009.

[2] A.Y. Starikovskii, Plasma supported combustion, Proc. Combust. Inst. 30 (2005) 2405-2417. doi:10.1016/j.proci.2004.08.272.

[3] S.M. Starikovskaia, Plasma assisted ignition and combustion, J. Phys. D: Appl. Phys. 39 (2006) R265-R299. doi:10.1088/0022-3727/39/16/R01.

[4] S.M. Starikovskaia, A.Y. Starikovskii, Plasma-Assisted Ignition and Combustion, in: M. Lackner, F. Winter, A.K. Agarwal (Eds.), Handbook of Combustion, Wiley-VCH Verlag GmbH \& Co. KGaA, 2010. http://dx.doi.org/10.1002/9783527628148.hoc075.

[5] A. Starikovskiy, N. Aleksandrov, Plasma-assisted ignition and combustion, Prog. Energy Combust. Sci. 39 (2013) 61-110. doi:10.1016/j.pecs.2012.05.003.

[6] LXcat. http://www.lxcat.net.

[7] G.J.M. Hagelaar, L.C. Pitchford, Solving the Boltzmann equation to obtain electron transport coefficients and rate coefficients for fluid models, Plasma Sources Sci. Technol. 14 (2005) 722-733. doi:10.1088/0963-0252/14/4/011.

[8] I. Glassman, R.A. Yetter, Combustion, 4th edition, Academic Press, 2008.

[9] M. Uddi, N. Jiang, E. Mintusov, I.V. Adamovich, W.R. Lempert, Atomic oxygen measurements in air and air/fuel nanosecond pulse discharges by two photon laser induced fluorescence, Proc. Combust. Inst. 32 (2009) 929-936. doi:10.1016/j.proci.2008.06.049. 
10] W. Sun, M. Uddi, S.H. Won, T. Ombrello, C. Carter, Y. Ju, Kinetic effects of non-equilibrium plasma-assisted methane oxidation on diffusion flame extinction limits, Combust. Flame. 159 (2012) 221-229. doi:10.1016/j.combustflame.2011.07.008.

[11] T. Ombrello, S.H. Won, Y. Ju, S. Williams, Flame propagation enhancement by plasma excitation of oxygen. Part II: Effects of $\mathrm{O}_{2}\left(a^{1} \Delta_{\mathrm{g}}\right)$, Combust. Flame. 157 (2010) 1916-1928. doi:10.1016/j.combustflame.2010.02.004.

[12] A.M. Starik, V.E. Kozlov, N.S. Titova, On mechanisms of a flame velocity increase upon activation of $\mathrm{O}_{2}$ molecules in electrical discharge, J. Phys. D: Appl. Phys. 41 (2008) 125206. doi:10.1088/0022-3727/41/12/125206.

[13] A.M. Starik, V.E. Kozlov, N.S. Titova, On the influence of singlet oxygen molecules on the speed of flame propagation in methane-air mixture, Combust. Flame. 157 (2010) 313-327. doi:10.1016/j.combustflame.2009.11.008.

[14] N.A. Popov, Effect of singlet oxygen $\mathrm{O}_{2}\left(a^{1} \Delta_{\mathrm{g}}\right)$ molecules produced in a gas discharge plasma on the ignition of hydrogen-oxygen mixtures, Plasma Sources Sci. Technol. 20 (2011) 045002. doi:10.1088/0963-0252/20/4/045002.

[15] N.A. Popov, Plasma assisted ignition of combustible mixtures. Effect of electronically excited $\mathrm{O}\left({ }^{1} \mathrm{D}\right)$ atoms and vibrationally excited molecules, in: 53rd AIAA Aerospace Sciences Meeting, AIAA 2015-0410, Kissimmee, Florida, 2015. doi:10.2514/6.2015-0410.

[16] F.E. Niles, Survey of Two-Body and Three-Body Reaction-Rate Coefficients for the Ionized Stratosphere and Mesosphere, AD776950, BRL1702, Ballistic Research Laboratories, Aberdeen Proving Ground, MD, 1974.

[17] M.H. Bortner, T. Baurer, eds., Defense Nuclear Agency Reaction Rate Handbook, Second Edition, Revision No. 9, DNA-1948H-Rev 9, 1983.

[18] Y. Ikezoe, S. Matsuoka, M. Takebe, A. Viggiano, Gas Phase Ion-Molecule Reaction Rate Constants Through 1986, Ion Reaction Research Group of the Mass Spectroscopy Society of Japan, Tokyo, Japan, 1987.

[19] V.G. Anicich, Evaluated Bimolecular Ion-Molecule Gas Phase Kinetics of Positive Ions for Use in Modeling Planetary Atmospheres, Cometary Comae, and Interstellar Clouds, J. Phys. Chem. Ref. Data. 22 (1993) 1469-1569. doi:10.1063/1.555940.

[20] D. McElroy, C. Walsh, A.J. Markwick, M.A. Cordiner, K. Smith, T.J. Millar, The UMIST database for astrochemistry 2012, Astron. Astrophys. 550 (2013) A36. doi:10.1051/00046361/201220465.

[21] N.G. Dautov, A.M. Starik, Investigation of the Effect of Vibrational Excitation of Molecules on the Kinetics of Combustion of an $\mathrm{H}_{2}+\mathrm{O}_{2}$ Mixture, High Temp. 32 (1994) 210-217.

[22] A.M. Starik, N.G. Dautov, On a Possibility of Promotion of Combustion for $\mathrm{H}_{2}-\mathrm{O}_{2}$ Mixture by Excitation of Molecular Vibrational Degrees of Freedom, Phys. Dokl. 39 (1994) 424-429.

[23] S.M. Starikovskaia, A.Y. Starikovskii, D.V. Zatsepin, Hydrogen oxidation in a stoichiometric hydrogen-air mixture in the fast ionization wave, Combust. Theory Model. 5 (2001) 97-129. doi:10.1088/1364-7830/5/1/306.

[24] N.L. Aleksandrov, S.V. Kindysheva, I.N. Kosarev, S.M. Starikovskaia, A.Y. Starikovskii, Mechanism of ignition by non-equilibrium plasma, Proc. Combust. Inst. 32 (2009) 205-212. doi:10.1016/j.proci.2008.06.124.

[25] I.V. Adamovich, I. Choi, N. Jiang, J.-H. Kim, S. Keshav, W.R. Lempert, et al., Plasma assisted ignition and high-speed flow control: non-thermal and thermal effects, Plasma Sources Sci. Technol. 18 (2009) 034018. doi:10.1088/0963-0252/18/3/034018.

[26] S. Nagaraja, V. Yang, Z. Yin, I. Adamovich, Ignition of hydrogen-air mixtures using pulsed nanosecond dielectric barrier plasma discharges in plane-to-plane geometry, Combust. Flame. 161 (2014) 1026-1037. doi:10.1016/j.combustflame.2013.10.007. 
[27] N. Tsolas, K. Togai, Z. Yin, K. Frederickson, R.A. Yetter, W.R. Lempert, et al., Plasma Flow Reactor Studies of $\mathrm{H}_{2} / \mathrm{O}_{2} / \mathrm{Ar}$ Kinetics, Combust. Flame. Accepted.

[28] A.E. Lutz, R.J. Kee, J.A. Miller, Senkin: A Fortran Program for Predicting Homogenous Gas Phase Chemical Kinetics with Sensitivity Analysis, SAND87-8248, Sandia National Laboratories, Livermore, CA, 1988.

[29] S. Pancheshnyi, B. Eismann, G.J.M. Hagelaar, L.C. Pitchford, Computer Code ZDPlasKin, University of Toulouse, LAPLACE, CNRS-UPS-INP, Toulouse, France, 2008. http://www.zdplaskin.laplace.univ-tlse.fr.

[30] I.V. Adamovich, M. Nishihara, I. Choi, M. Uddi, W.R. Lempert, Energy coupling to the plasma in repetitive nanosecond pulse discharges, Phys. Plasmas. 16 (2009) 113505. doi:10.1063/1.3264740.

[31] M. Caracotsios, W.E. Stewart, Sensitivity analysis of initial value problems with mixed odes and algebraic equations, Comp. Chem. Eng. 9 (1985) 359-365. doi:10.1016/00981354(85)85014-6.

[32] U. Nowak, J. Warnatz, Sensitivity Analysis in Aliphatic Hydrocarbon Combustion, in: A.L. Kuhl, J.R. Bowen, J.-C. Leyer, A. Borisov (Eds.), Dynamics of Reactive Systems Part I: Flames; Part II: Heterogeneous Combustion and Applications, American Institute of Aeronautics and Astronautics, Washington, D.C., 1988: pp. 87-103. http://dx.doi.org/10.2514/5.9781600865879.0087.0103.

[33] T. Turányi, Applications of sensitivity analysis to combustion chemistry, Reliability Eng. Sys. Safety,. 57 (1997) 41-48. doi:10.1016/S0951-8320(97)00016-1.

[34] X. Yang, K. Togai, R.A. Yetter, Y. Ju, Preliminary validation of HP-Mech/plasma for $\mathrm{H}_{2} / \mathrm{O}_{2} / \mathrm{NO}$ and methane $/ \mathrm{O}_{3}$ reaction systems, (In preparation).

[35] M.P. Burke, M. Chaos, Y. Ju, F.L. Dryer, S.J. Klippenstein, Comprehensive $\mathrm{H}_{2} / \mathrm{O}_{2}$ kinetic model for high-pressure combustion, Int. J. Chem. Kinet. 44 (2012) 444-474. doi:10.1002/kin.20603.

[36] J.E. Dove, H. Teitelbaum, The vibrational relaxation of $\mathrm{H}_{2}$. I. Experimental measurements of the rate of relaxation by $\mathrm{H}_{2}, \mathrm{He}, \mathrm{Ne}$, Ar, and Kr, Chem. Phys. 6 (1974) 431-444. doi:10.1016/0301-0104(74)85027-5.

[37] M. Agúndez, J.R. Goicoechea, J. Cernicharo, A. Faure, E. Roueff, The chemistry of vibrationally excited $\mathrm{H}_{2}$ in the interstellar medium, Astrophys. J. 713 (2010) 662-670. doi:10.1088/0004-637X/713/1/662.

[38] A. Burcat, B. Ruscic, Third Millenium Ideal Gas and Condensed Phase Thermochemical Database for Combustion (with Update from Active Thermochemical Tables), ANL-05/20 and TAE 960, Technion-IIT and Argonne National Laboratory, 2005. http://dx.doi.org/10.2172/925269.

[39] Y. Liu, F. Shakib, M. Vinokur, A comparison of internal energy calculation methods for diatomic molecules, Phys. Fluids A. 2 (1990) 1884-1902. doi:10.1063/1.857663.

[40] J. Balamuta, M.F. Golde, Quenching of metastable $\mathrm{Ar}$, $\mathrm{Kr}$, and $\mathrm{Xe}$ atoms by oxygen-containing compounds: A resonance fluorescence study of reaction products, J. Chem. Phys. 76 (1982) 2430-2440. doi:10.1063/1.443272.

[41] J. Balamuta, M.F. Golde, Y.-S. Ho, Product distributions in the reactions of excited noble-gas atoms with hydrogen-containing compounds, J. Chem. Phys. 79 (1983) 2822-2830. doi:10.1063/1.446103.

[42] C.K. Law, Combustion Physics, Cambridge University Press, Cambridge, New York, 2010.

[43] H. Ryzko, Drift velocity of electrons and ions in dry and humid air and in water vapour, Proc. Phys. Soc. 85 (1965) 1283. doi:10.1088/0370-1328/85/6/327. 
[44] W.T. Wyatt Jr., Computed Electron Drift Velocity in Moist Air, Technical Report 1890, U.S. Army Engineer Research and Development Laboratories, Fort Belvoir, VA, 1967.

[45] M.A. Mueller, T.J. Kim, R.A. Yetter, F.L. Dryer, Flow reactor studies and kinetic modeling of the $\mathrm{H}_{2} / \mathrm{O}_{2}$ reaction, Int. J. Chem. Kinet. 31 (1999) 113-125. doi:10.1002/(SICI)10974601(1999)31:2<113::AID-KIN5>3.0.CO;2-0.

[46] J.T. Gudmundsson, E.G. Thorsteinsson, Oxygen discharges diluted with argon: dissociation processes, Plasma Sources Sci. Technol. 16 (2007) 399. doi:10.1088/0963-0252/16/2/025.

[47] P.M. Banks, G. Kockarts, Aeronomy, Part A, Academic Press, New York, 1973. 


\section{Figures}

1

2

3

4

5

6

8

Figure 1. Equivalent circuit of the DBD system. 


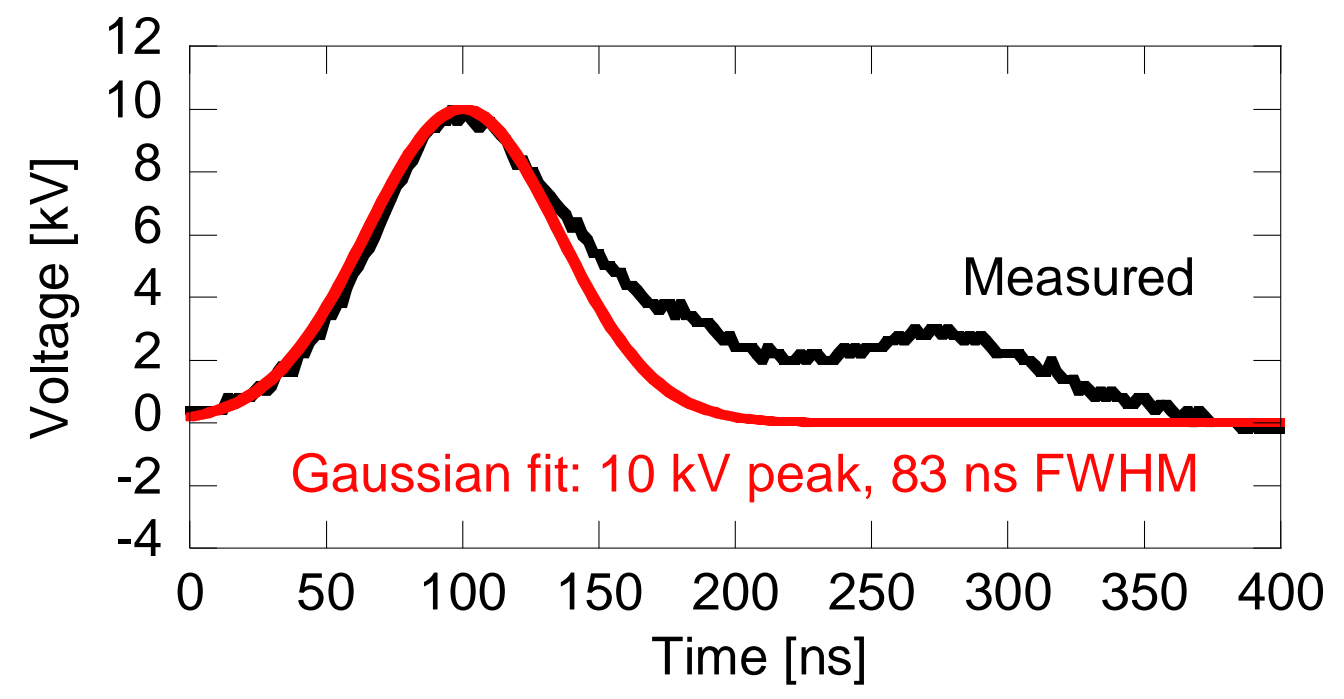

Figure 2. Measured and modeled voltage pulse profile applied to the electrodes. 


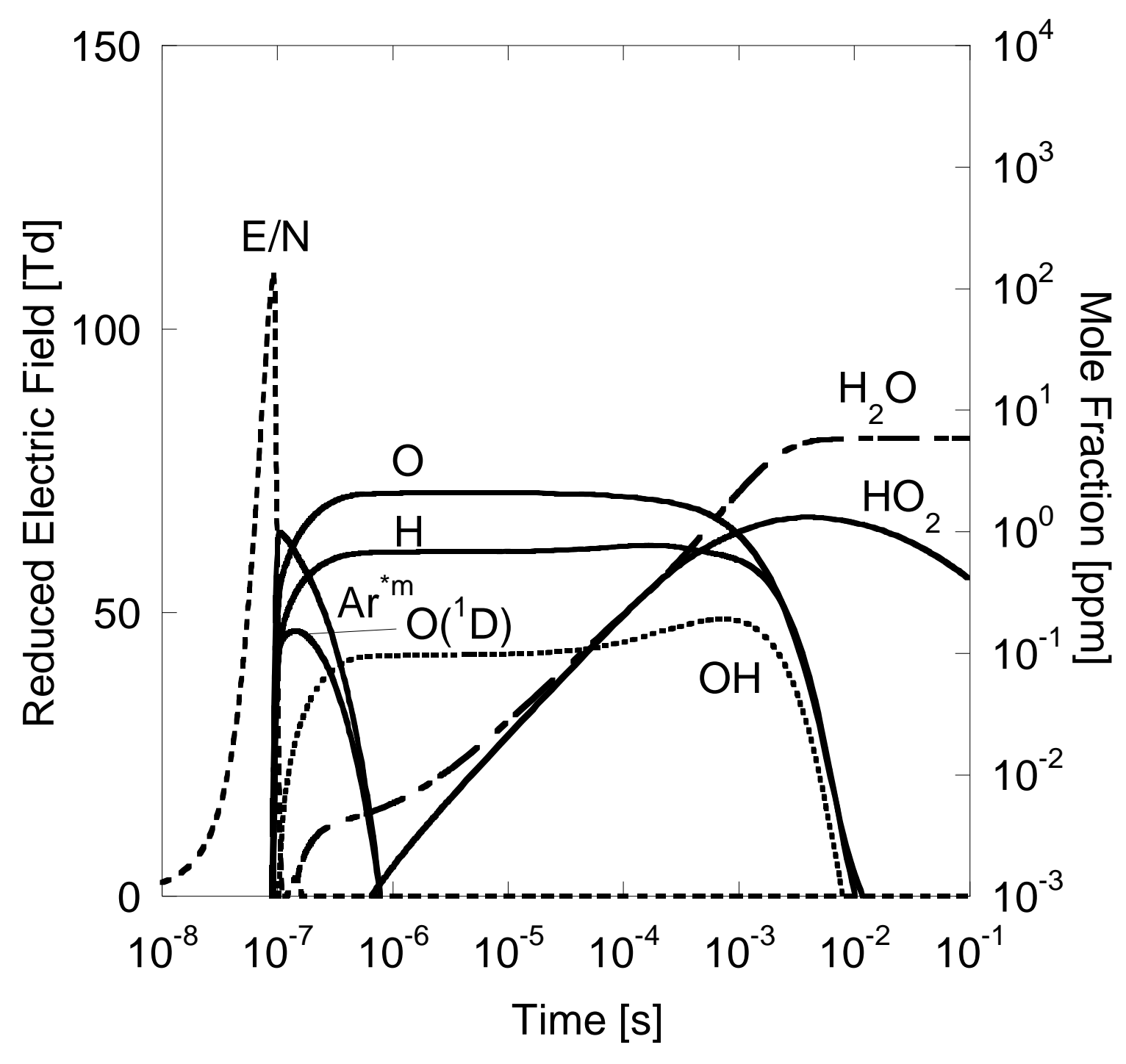

Figure 3. Time evolution of the reduced electric field and species mole fractions for a single discharge pulse with a peak voltage of $10 \mathrm{kV}$. The initial mixture composition is $2000 \mathrm{ppm} \mathrm{H}_{2}, 3000 \mathrm{ppm} \mathrm{O}_{2}$, with the balance Ar. The temperature and pressure are $T=668 \mathrm{~K}$ and $P=1 \mathrm{~atm}$, respectively. 

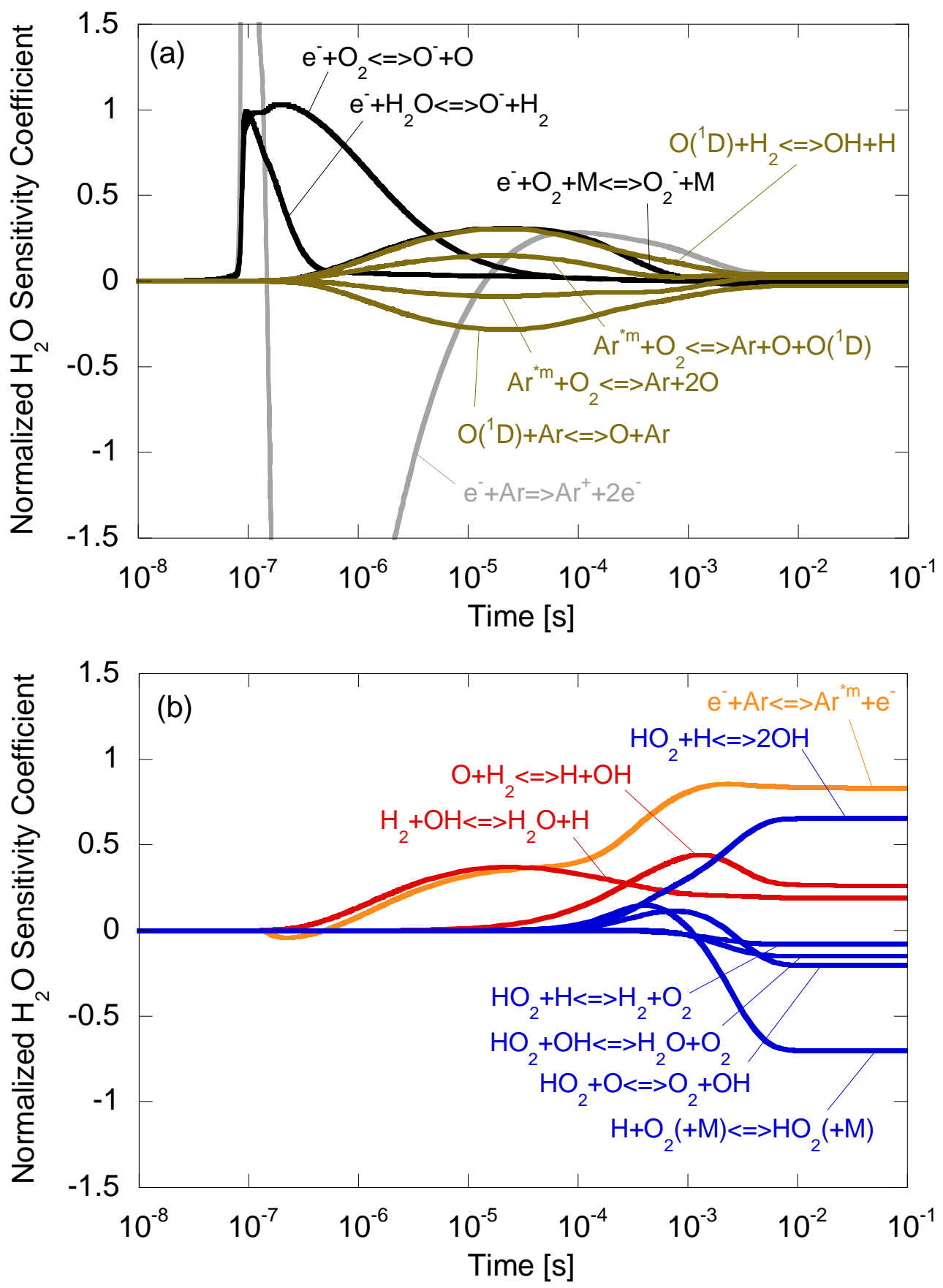

Figure 4. Normalized sensitivity coefficients for the $\mathrm{H}_{2} \mathrm{O}$ mole fraction for a single discharge pulse with a peak voltage of $10 \mathrm{kV}$ for reactions of significance during (a) short time scales and (b) long time scales. The initial mixture composition is $2000 \mathrm{ppm} \mathrm{H}_{2}, 3000 \mathrm{ppm} \mathrm{O}_{2}$, with the balance Ar. The temperature and pressure are $T=$ $668 \mathrm{~K}$ and $P=1$ atm, respectively. 

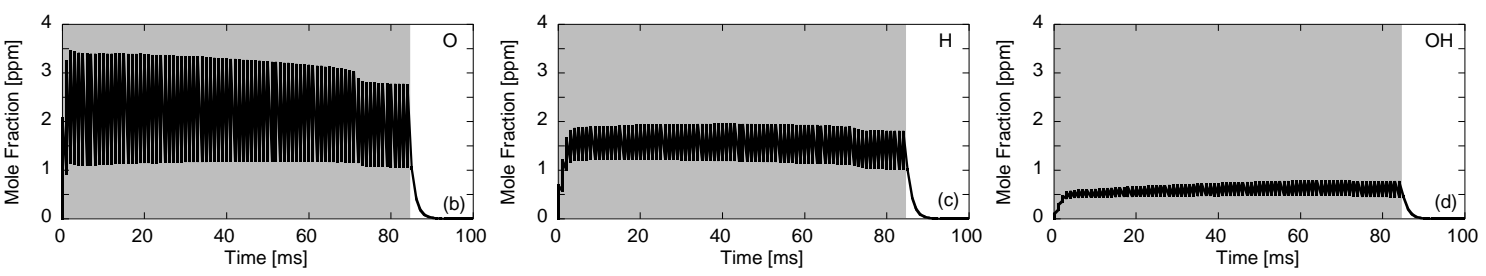

Figure 5. Time evolution of the (a) major species and (b)-(d) minor species in the isothermal region of the plasma flow reactor described in Ref. [27]. The gray region corresponds to the residence time in the plasma region where the pulse repetition rate of the plasma discharge is $1 \mathrm{kHz}$ and the pulse peak voltage is $10 \mathrm{kV}$. The initial mixture composition is $2000 \mathrm{ppm} \mathrm{H}_{2}, 3000 \mathrm{ppm} \mathrm{O}_{2}$, with the balance Ar. The temperature and pressure are $T=668 \mathrm{~K}$ and $P=1$ atm, respectively. 

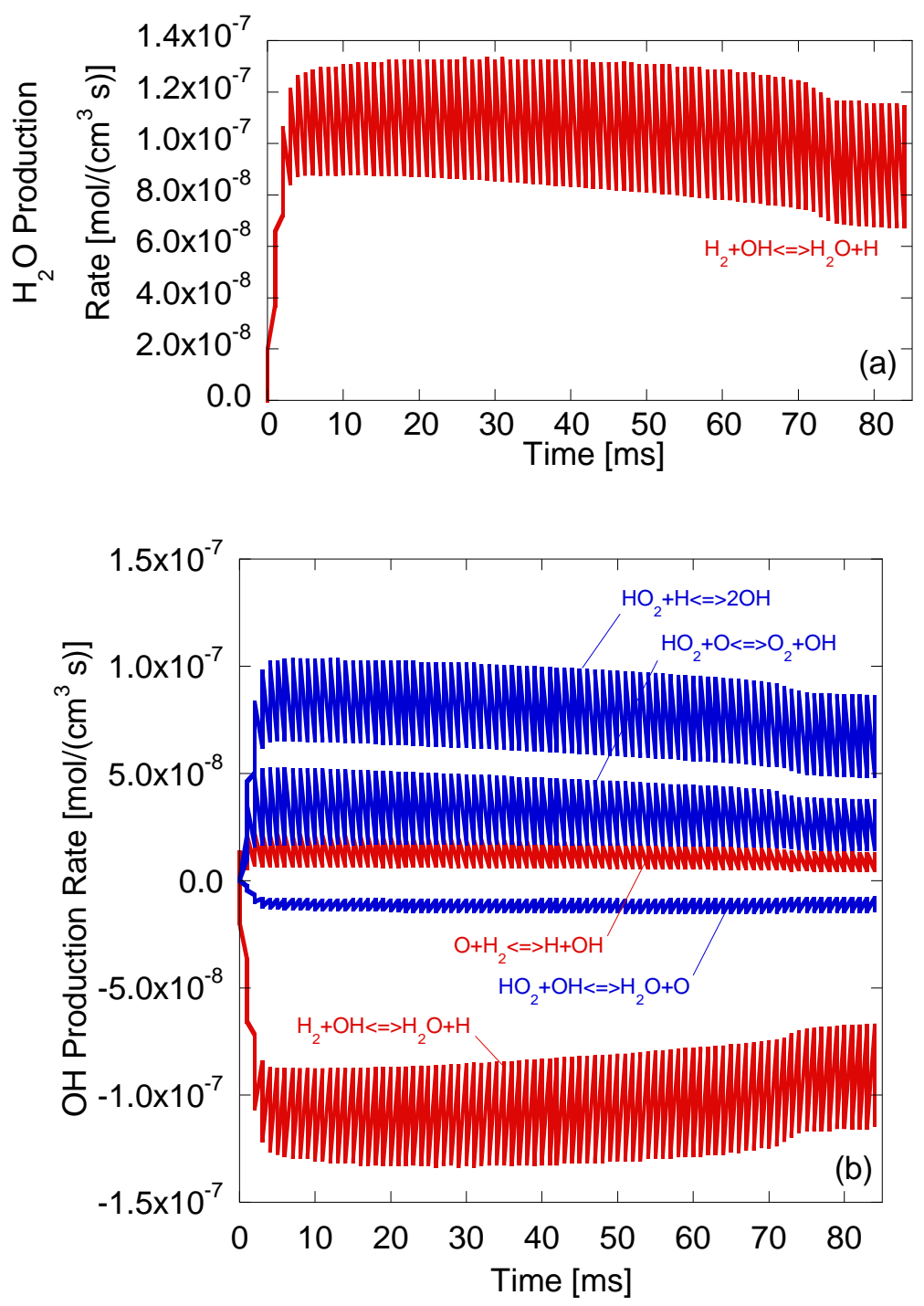

Figure 6. Time evolution of the reaction flux for the most significant reactions leading to the formation and consumption of (a) $\mathrm{H}_{2} \mathrm{O}$ and (b) $\mathrm{OH}$ in the plasma region where the pulse repetition rate of the plasma discharge is $1 \mathrm{kHz}$ and the pulse peak voltage is $10 \mathrm{kV}$. The initial mixture composition is $2000 \mathrm{ppm} \mathrm{H}_{2}, 3000 \mathrm{ppm} \mathrm{O}_{2}$, with the balance Ar. The temperature and pressure are $T=668 \mathrm{~K}$ and $P=1 \mathrm{~atm}$, respectively. 

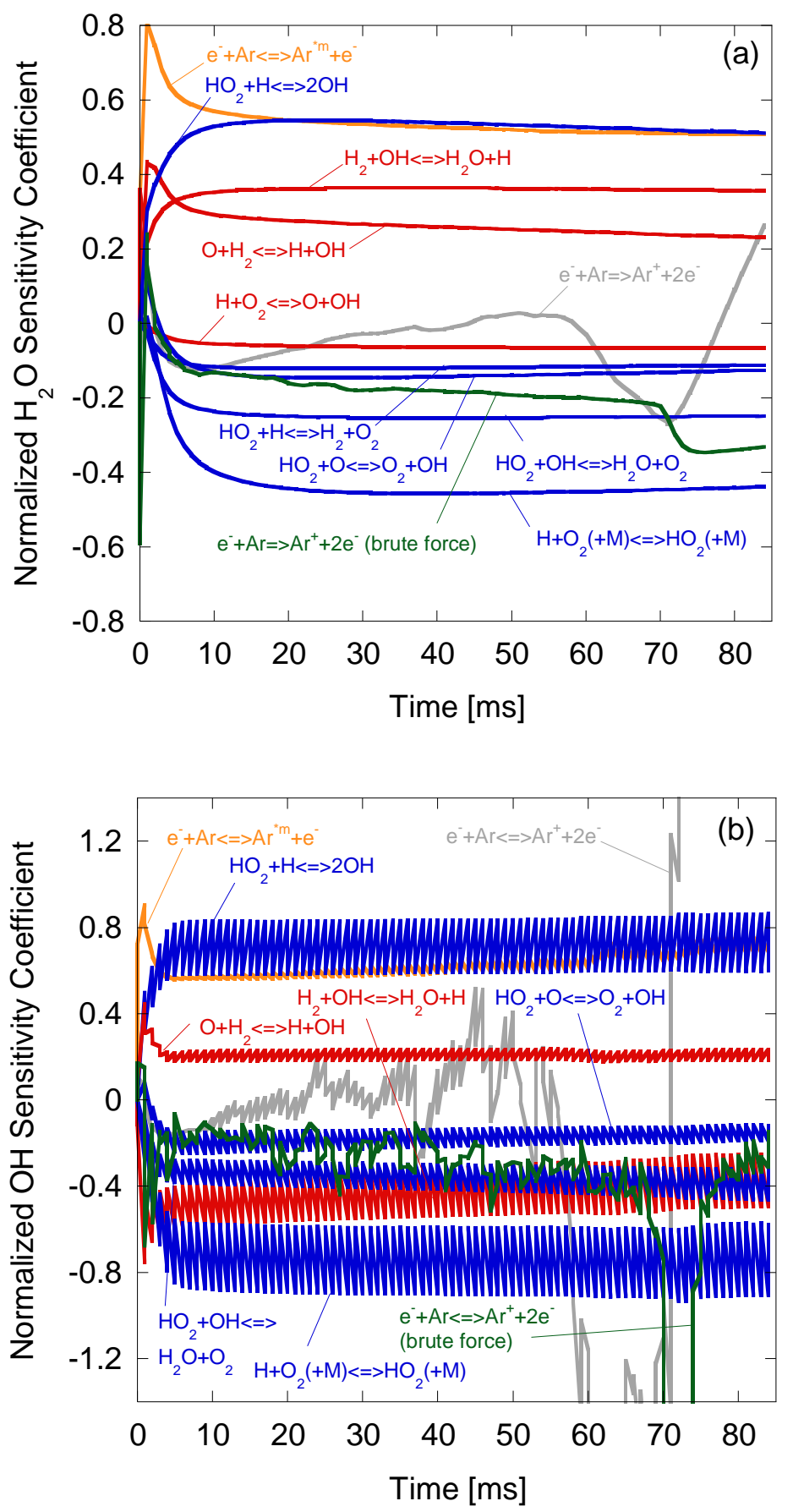

Figure 7. Normalized sensitivity coefficients for (a) the $\mathrm{H}_{2} \mathrm{O}$ mole fraction and (b) the $\mathrm{OH}$ mole fraction in the plasma region where the pulse repetition rate of the plasma discharge is $1 \mathrm{kHz}$ and the pulse peak voltage is $10 \mathrm{kV}$. The initial mixture composition is $2000 \mathrm{ppm} \mathrm{H}_{2}, 3000 \mathrm{ppm} \mathrm{O}_{2}$, with the balance Ar. The temperature and pressure are $T=668 \mathrm{~K}$ and $P=1 \mathrm{~atm}$, respectively. 

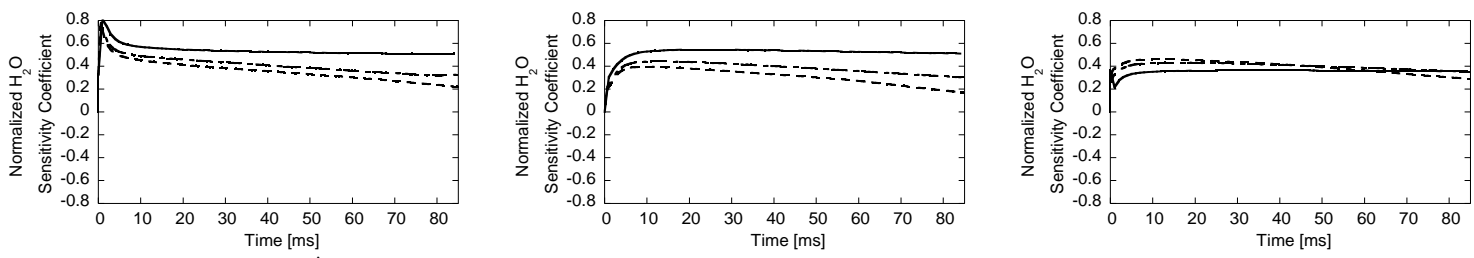

(R5) $\mathrm{e}^{-}+\mathbf{A r} \leftrightarrow A \mathbf{r}^{*} \mathrm{~m}+\mathrm{e}^{-}$

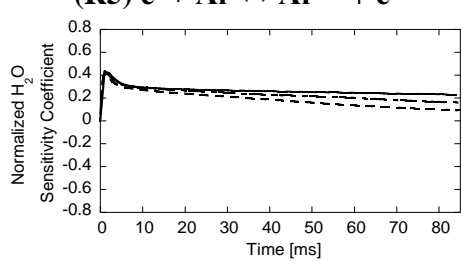

(R8) $\mathrm{HO}_{2}+\mathrm{H} \leftrightarrow 2 \mathrm{OH}$

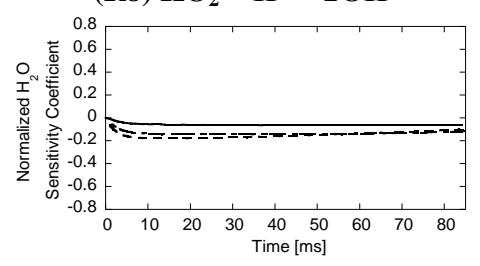

(R9) $\mathrm{H}_{2}+\mathrm{OH} \leftrightarrow \mathrm{H}_{2} \mathrm{O}+\mathrm{H}$

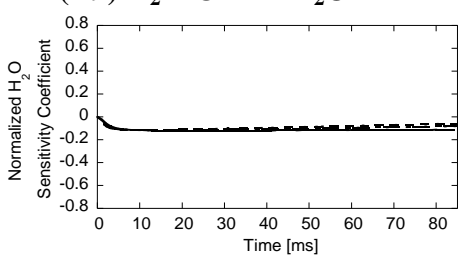

(R2) $\mathrm{H}+\mathrm{O}_{2} \leftrightarrow \mathrm{O}+\mathrm{OH}$

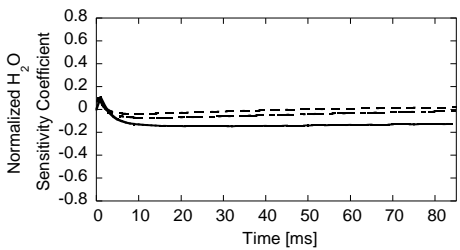

(R7) $\mathrm{HO}_{2}+\mathrm{O} \leftrightarrow \mathrm{O}_{2}+\mathrm{OH}$

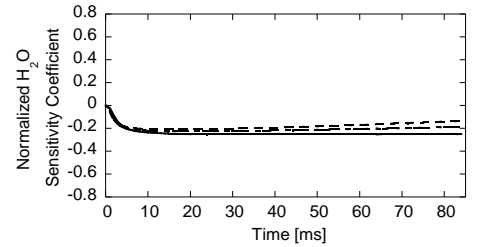

(R11) $\mathrm{HO}_{2}+\mathrm{OH} \leftrightarrow \mathrm{H}_{2} \mathrm{O}+\mathrm{O}_{2}$
(R12) $\mathrm{HO}_{2}+\mathrm{H} \leftrightarrow \mathrm{H}_{2}+\mathrm{O}_{2}$

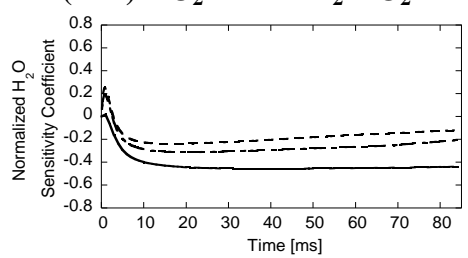

(R6) $\mathrm{H}+\mathrm{O} 2(+\mathrm{M}) \leftrightarrow \mathrm{HO}_{2}(+\mathrm{M})$

Figure 8. Dependence of the normalized $\mathrm{H}_{2} \mathrm{O}$ mole fraction sensitivity coefficients on the pulse repetition rate of the plasma discharge where the pulse peak voltage is $10 \mathrm{kV}$. The solid line $(-)$ denotes a pulse repetition rate of $1 \mathrm{kHz}$, the dash-dot line (-- -), a pulse repetition rate of $3 \mathrm{kHz}$, and the broken line (- - -), a pulse repetition rate of $5 \mathrm{kHz}$. The initial mixture composition is $2000 \mathrm{ppm} \mathrm{H}_{2}, 3000 \mathrm{ppm} \mathrm{O}_{2}$, with the balance Ar. The temperature and pressure are $T=668 \mathrm{~K}$ and $P=1 \mathrm{~atm}$, respectively. 
Figure 9. Time evolution of the reduced electric field and species mole fractions for a single discharge pulse with a peak voltage of $10 \mathrm{kV}$. The initial mixture composition is $2000 \mathrm{ppm} \mathrm{H}_{2}, 3000 \mathrm{ppm} \mathrm{O}_{2}$, with the balance Ar. The temperature and pressure are $T=921 \mathrm{~K}$ and $P=1 \mathrm{~atm}$, respectively. 


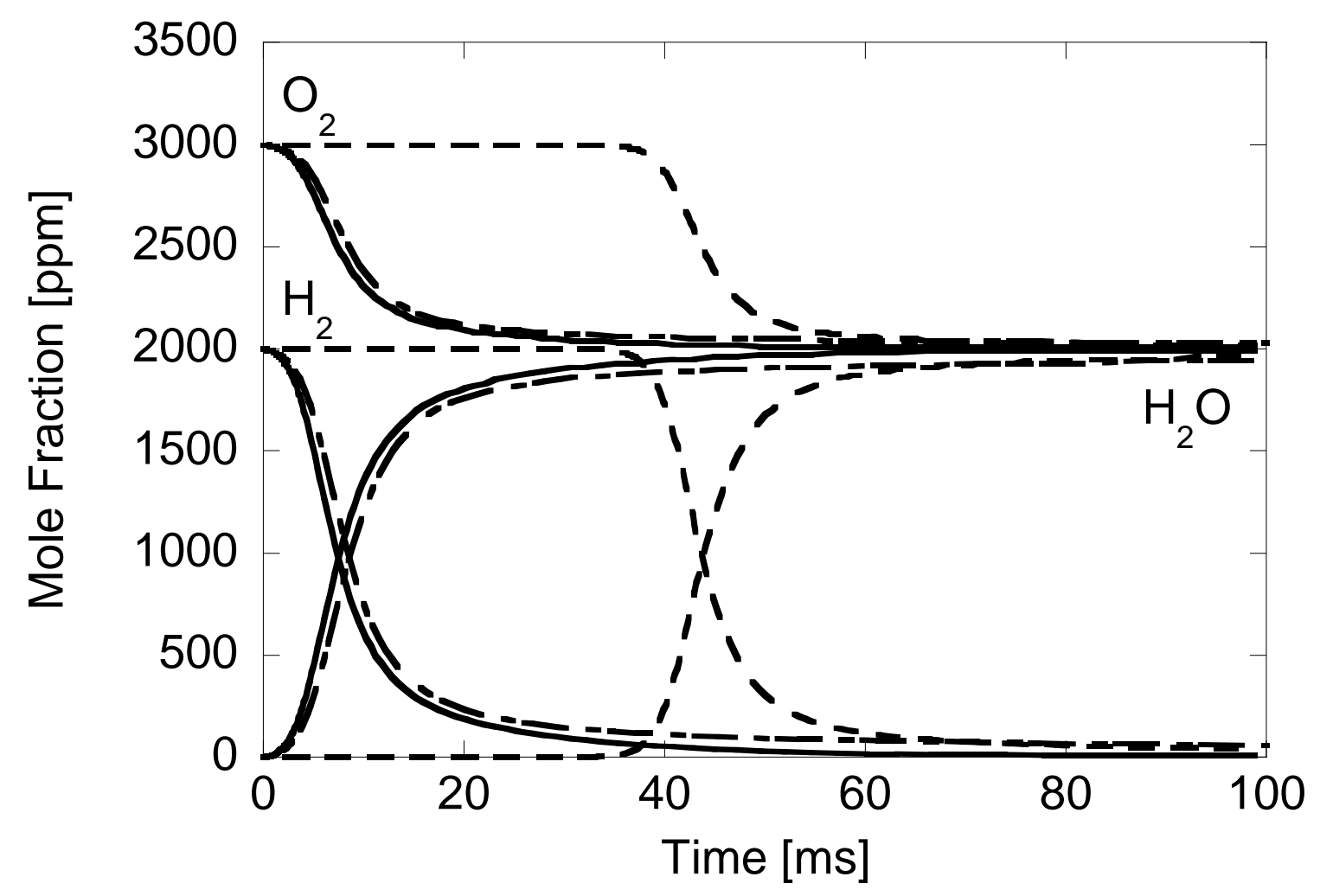

Figure 10. Time evolution of the major species for a $\mathrm{H}_{2} / \mathrm{O}_{2} / \mathrm{Ar}$ mixture reacting at conditions above the second explosion limit. The broken line (- - ) denotes the thermal reaction, the dash-dot line (- - - ) denotes the single discharge pulse, and the solid line (- ${ }_{-}$) denotes the case with 62 pulses corresponding to a pulse repetition rate of $1 \mathrm{kHz}$. The pulse peak voltage is $10 \mathrm{kV}$ where applied. The initial mixture composition is $2000 \mathrm{ppm} \mathrm{H}_{2}, 3000$ ppm $\mathrm{O}_{2}$, with the balance Ar. The temperature and pressure are $T=921 \mathrm{~K}$ and $P=1 \mathrm{~atm}$, respectively. 
Figure 11. Normalized sensitivity coefficients for $\mathrm{H}_{2} \mathrm{O}$ when the pulse repetition rate of the discharge is $1 \mathrm{kHz}$ and the pulse peak voltage is $10 \mathrm{kV}$. The initial mixture composition is $2000 \mathrm{ppm} \mathrm{H}_{2}, 3000 \mathrm{ppm} \mathrm{O}_{2}$, with the balance Ar. The temperature and pressure are $T=921 \mathrm{~K}$ and $P=1 \mathrm{~atm}$, respectively. 


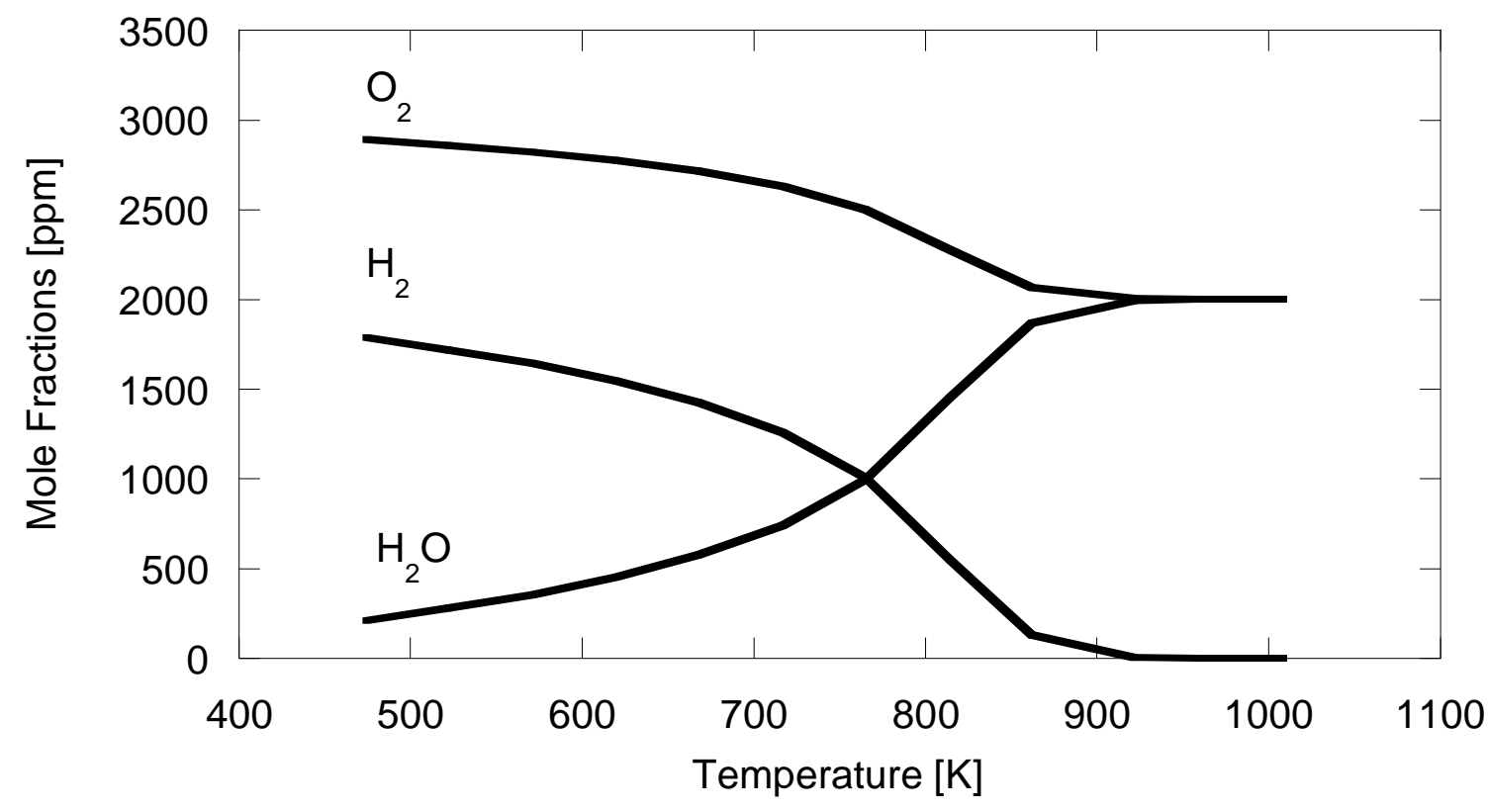

Figure 12. Mixture composition in mole fractions at the exit of the plasma flow reactor for various reactor temperatures. The initial mixture composition is $2000 \mathrm{ppm} \mathrm{H}, 3000 \mathrm{ppm} \mathrm{O}$, with the balance Ar. The pressure is $P=1 \mathrm{~atm}$. The plasma pulse repetition rate is $1 \mathrm{kHz}$ and the pulse peak voltage is $10 \mathrm{kV}$. 


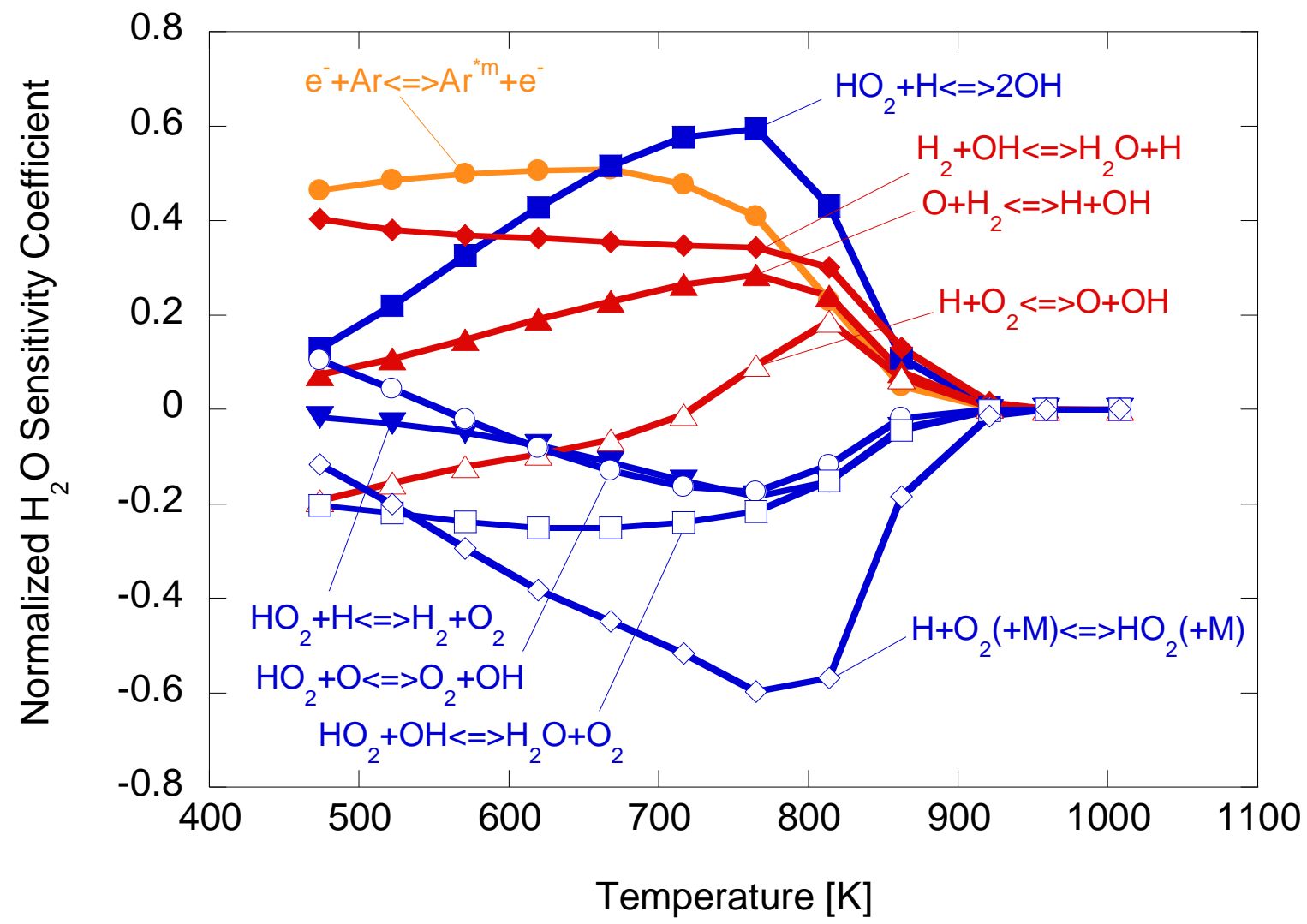

Figure 13. Normalized sensitivity coefficients of the $\mathrm{H}_{2} \mathrm{O}$ mole fraction at the plasma flow reactor exit for various reactor temperatures. The initial mixture composition is $2000 \mathrm{ppm} \mathrm{H}_{2}, 3000 \mathrm{ppm} \mathrm{O}_{2}$, with the balance Ar. The pressure is $P=1 \mathrm{~atm}$. The plasma pulse repetition rate is $1 \mathrm{kHz}$ and the pulse peak voltage is $10 \mathrm{kV}$. 
Figure 1. Equivalent circuit of the DBD system.

Figure 2. Measured and modeled voltage pulse profile applied to the electrodes.

Figure 3. Time evolution of the reduced electric field and species mole fractions for a single discharge pulse with a peak voltage of $10 \mathrm{kV}$. The initial mixture composition is $2000 \mathrm{ppm} \mathrm{H}_{2}, 3000 \mathrm{ppm} \mathrm{O}_{2}$, with the balance Ar. The temperature and pressure are $T=668 \mathrm{~K}$ and $P=1 \mathrm{~atm}$, respectively.

Figure 4. Normalized sensitivity coefficients for the $\mathrm{H}_{2} \mathrm{O}$ mole fraction for a single discharge pulse with a peak voltage of $10 \mathrm{kV}$ for reactions of significance during (a) short time scales and (b) long time scales. The initial mixture composition is $2000 \mathrm{ppm} \mathrm{H}_{2}, 3000 \mathrm{ppm} \mathrm{O}_{2}$, with the balance Ar. The temperature and pressure are $T=668$ $\mathrm{K}$ and $P=1 \mathrm{~atm}$, respectively.

Figure 5. Time evolution of the (a) major species and (b)-(d) minor species in the isothermal region of the plasma flow reactor described in Ref. [27]. The gray region corresponds to the residence time in the plasma region where the pulse repetition rate of the plasma discharge is $1 \mathrm{kHz}$ and the pulse peak voltage is $10 \mathrm{kV}$. The initial mixture composition is $2000 \mathrm{ppm} \mathrm{H}_{2}, 3000 \mathrm{ppm} \mathrm{O}$, with the balance Ar. The temperature and pressure are $T=668 \mathrm{~K}$ and $P=1$ atm, respectively.

Figure 6. Time evolution of the reaction flux for the most significant reactions leading to the formation and consumption of (a) $\mathrm{H}_{2} \mathrm{O}$ and (b) $\mathrm{OH}$ in the plasma region where the pulse repetition rate of the plasma discharge is $1 \mathrm{kHz}$ and the pulse peak voltage is $10 \mathrm{kV}$. The initial mixture composition is $2000 \mathrm{ppm} \mathrm{H}_{2}, 3000 \mathrm{ppm} \mathrm{O}_{2}$, with the balance Ar. The temperature and pressure are $T=668 \mathrm{~K}$ and $P=1 \mathrm{~atm}$, respectively.

Figure 7. Normalized sensitivity coefficients for (a) the $\mathrm{H}_{2} \mathrm{O}$ mole fraction and (b) the $\mathrm{OH}$ mole fraction in the plasma region where the pulse repetition rate of the plasma discharge is $1 \mathrm{kHz}$ and the pulse peak voltage is $10 \mathrm{kV}$. The initial mixture composition is $2000 \mathrm{ppm} \mathrm{H}, 3000 \mathrm{ppm} \mathrm{O}_{2}$, with the balance Ar. The temperature and pressure are $T=668 \mathrm{~K}$ and $P=1 \mathrm{~atm}$, respectively.

Figure 8. Dependence of the normalized $\mathrm{H}_{2} \mathrm{O}$ mole fraction sensitivity coefficients on the pulse repetition rate of the plasma discharge where the pulse peak voltage is $10 \mathrm{kV}$. The solid line $(-)$ denotes a pulse repetition rate of 1 $\mathrm{kHz}$, the dash-dot line (- - ), a pulse repetition rate of $3 \mathrm{kHz}$, and the broken line (- - -), a pulse repetition rate of $5 \mathrm{kHz}$. The initial mixture composition is $2000 \mathrm{ppm} \mathrm{H}_{2}, 3000 \mathrm{ppm} \mathrm{O}_{2}$, with the balance Ar. The temperature and pressure are $T=668 \mathrm{~K}$ and $P=1 \mathrm{~atm}$, respectively.

Figure 9. Time evolution of the reduced electric field and species mole fractions for a single discharge pulse with a peak voltage of $10 \mathrm{kV}$. The initial mixture composition is $2000 \mathrm{ppm} \mathrm{H}_{2}, 3000 \mathrm{ppm} \mathrm{O}_{2}$, with the balance Ar. The temperature and pressure are $T=921 \mathrm{~K}$ and $P=1 \mathrm{~atm}$, respectively.

Figure 10. Time evolution of the major species for a $\mathrm{H}_{2} / \mathrm{O}_{2} / \mathrm{Ar}$ mixture reacting at conditions above the second explosion limit. The broken line (- - ) denotes the thermal reaction, the dash-dot line (- - -) denotes the single discharge pulse, and the solid line (- ${ }_{-}$) denotes the case with 62 pulses corresponding to a pulse repetition rate of $1 \mathrm{kHz}$. The pulse peak voltage is $10 \mathrm{kV}$ where applied. The initial mixture composition is $2000 \mathrm{ppm} \mathrm{H}_{2}, 3000 \mathrm{ppm}$ $\mathrm{O}_{2}$, with the balance Ar. The temperature and pressure are $T=921 \mathrm{~K}$ and $P=1 \mathrm{~atm}$, respectively.

Figure 11. Normalized sensitivity coefficients for $\mathrm{H}_{2} \mathrm{O}$ when the pulse repetition rate of the discharge is $1 \mathrm{kHz}$ and the pulse peak voltage is $10 \mathrm{kV}$. The initial mixture composition is $2000 \mathrm{ppm} \mathrm{H}_{2}, 3000 \mathrm{ppm} \mathrm{O}$, with the balance Ar. The temperature and pressure are $T=921 \mathrm{~K}$ and $P=1 \mathrm{~atm}$, respectively.

Figure 12. Mixture composition in mole fractions at the exit of the plasma flow reactor for various reactor temperatures. The initial mixture composition is $2000 \mathrm{ppm} \mathrm{H}_{2}, 3000 \mathrm{ppm} \mathrm{O}_{2}$, with the balance Ar. The pressure is $P=1 \mathrm{~atm}$. The plasma pulse repetition rate is $1 \mathrm{kHz}$ and the pulse peak voltage is $10 \mathrm{kV}$.

Figure 13. Normalized sensitivity coefficients of the $\mathrm{H}_{2} \mathrm{O}$ mole fraction at the plasma flow reactor exit for various reactor temperatures. The initial mixture composition is $2000 \mathrm{ppm} \mathrm{H}_{2}, 3000 \mathrm{ppm} \mathrm{O}_{2}$, with the balance Ar. The pressure is $P=1 \mathrm{~atm}$. The plasma pulse repetition rate is $1 \mathrm{kHz}$ and the pulse peak voltage is $10 \mathrm{kV}$. 